FEDERAL RESERVE BANK OF SAN FRANCISCO

WORKING PAPER SERIES

\title{
The Disappointing Recovery of Output after 2009
}

\author{
John G. Fernald \\ Federal Reserve Bank of San Francisco \\ INSEAD \\ Robert E. Hall \\ Stanford University \\ James H. Stock \\ Harvard University \\ Mark W. Watson \\ Princeton University
}

June 2017

Working Paper 2017-14

http://www.frbsf.org/economic-research/publications/working-papers/wp2017-14.pdf

\section{Suggested citation:}

Fernald, John G., Robert E. Hall, James H. Stock, Mark W. Watson. 2017. “The Disappointing Recovery of Output after 2009” Federal Reserve Bank of San Francisco Working Paper 201714. http://www.frbsf.org/economic-research/publications/working-papers/wp2017-14.pdf

The views in this paper are solely the responsibility of the authors and should not be interpreted as reflecting the views of the Federal Reserve Bank of San Francisco or the Board of Governors of the Federal Reserve System. This paper was produced under the auspices of the Center for Pacific Basin Studies within the Economic Research Department of the Federal Reserve Bank of San Francisco. 
JOHN G. FERNALD

Federal Reserve Bank of San Francisco

INSEAD

ROBERT E. HALL

Stanford University

JAMES H. STOCK

Harvard University

MARK W. WATSON

Princeton University

\section{The Disappointing Recovery of Output after 2009}

June 17, 2017

ABSTRACT U.S. output has expanded only slowly since the recession trough in 2009, even though the unemployment rate has essentially returned to a precrisis, normal level. We use a growthaccounting decomposition to explore explanations for the output shortfall, giving full treatment to cyclical effects that, given the depth of the recession, should have implied unusually fast growth. We find that the growth shortfall has almost entirely reflected two factors: the slow growth of total factor productivity, and the decline in labor force participation. Both factors reflect powerful adverse forces that are largely unrelated to the financial crisis and recession-and that were in play before the recession.

ACKNOWLEDGMENTS We thank Laurence Ball, Vasco Curdia, David Romer, Glenn Rudebusch, John Williams, and Jonathan Wright; the seminar and conference participants at the Federal Reserve Bank of San Francisco, the Federal Reserve Bank of Boston, the Federal Reserve Bank of New York, and the Brookings Institution; our editor, Janice Eberly; and discussants Robert Barro and Lucrezia Reichlin. We also thank John Coglianese and Neil Gerstein for excellent research assistance. The views in this paper are solely the responsibility of the authors and should not be interpreted as reflecting the views of the Federal Reserve Bank of San Francisco, the Board of Governors of the Federal Reserve System, or the Business Cycle Dating Committee of the National Bureau of Economic Research. 
Why did U.S. output grow so slowly in the post-2009 recovery, especially relative to the recovery of the unemployment rate? The unemployment rate fell at a pace within the range of the previous three cyclical expansions—see figure 1, left panel, where the dashed arrows show changes in the unemployment rate from the troughs of recent recessions. In contrast, the figure's right panel shows that the growth of output since 2009 has fallen far short. Output per person — the solid line, in logs—fell sharply during the recession and, as of this writing, remains below any reasonable linear trend line extending its prerecession trajectory.

The dashed line in the right panel of figure 1 provides an alternative output path that removes the normal cyclical effects of the deep recession in a simple way, using Okun's (1962) law, as described later in this paper. The picture is striking: This line is nowhere close to a straight-line projection from the 2007 peak. Rather, cyclically adjusted output per person rose only slowly after 2007, and it then plateaued.

We argue for taking this dashed line seriously as the counterfactual path of output in the absence of the recession. Viewed relative to this path, what appears to be a slow recovery of output reflects something quite different: The U.S. economy suffered a deep recession superimposed on a sharply slowing trend.

We use Solow-style growth accounting to tease out the various components underlying the flattening of the dashed line. Two components explain nearly all the growth gap: slow growth in total factor productivity (TFP), and falling labor force participation. The participation decline causes cyclically adjusted hours worked per person to fall sharply. Slowly rising TFP and falling hours per person together imply flat cyclically adjusted output per person.

In this paper, we do not focus directly on the collapse of demand that began at the end of 2007 and worsened a great deal after the financial crisis at the end of 2008. This is not because we believe that the demand effects were small. In our estimates, the collapse in demand led to a very large cumulative loss in output, as measured by the area between the dashed, cyclically adjusted line and the solid line in the right panel of figure 1 . But by 2016, the economy had returned to full employment, so the disappointing level of output at that point reflected nondemand factors. 
The crucial question that arises from the growth accounting is whether the factors explaining the shortfall in some way reflect lasting effects of the recession on output - in other words hysteresis, for which three channels are the leading candidates: TFP, labor force participation, and the capital stock. We examine these three channels in detail to discern whether the endpoints of the corresponding variables in 2016 were influenced by the post-2007 experience of recession and slow recovery. Our answer is no. Instead, these factors reflect powerful adverse forces that are largely-if not entirely-unrelated to the financial crisis and recession.

The forces of slow growth of the labor force and of TFP were in play before the recession. The Congressional Budget Office (CBO 2006) and Stephanie Aaronson and others (2006) forecasted declines in participation as the baby boom generation retired and the 1960s to 1980s surge of women into the labor force plateaued. Also, before the recession, Stephen Oliner, Daniel Sichel, and Kevin Stiroh (2007) and Dale Jorgenson, Mun Ho, and Stiroh (2008) noted that TFP growth had slowed, though that slowdown is now more easily seen with the benefit of subsequent data as well as data revisions.

This said, it took time for these slow-growth trends to be appreciated. Figure 2 shows that, during the recovery, professional forecasters regularly overpredicted output growth, even while they were being too pessimistic about the recovery of the unemployment rate. These forecasts are representative of other real-time forecasts by the CBO, the Federal Open Market Committee (Lansing and Pyle 2015), and the Council of Economic Advisers. These overly optimistic GDP forecasts constitute an alternative framing of the disappointing recovery of output.

Although the broad trends in both participation and TFP appear to be essentially exogenous to the business cycle, investment is inherently endogenous. As many have noted, capital accumulation was lower than in previous recoveries. But we attribute this shortfall to the forces responsible for slower trend output growth. By mid-2016, the capital-output ratio was close to its prerecession trend line.

Under standard growth theory, slower TFP growth and falling participation should raise the capital-output ratio, because less investment is needed simply to keep pace with technology and the labor force. This higher capital-output ratio reduces the marginal product of capital and lowers the 
equilibrium real interest rate. By 2016, the cyclically adjusted capital-output ratio had returned to its trend growth path, but not above that path, as growth theory would suggest. Possibly, additional capital deepening lies ahead. Or other factors might have depressed the steady-state capital-output ratio. Germán Gutiérrez and Thomas Philippon (2016) argue that investment has been held back by rising market power, which lowers the marginal revenue product of capital and thus discourages capital formation. Lewis Alexander and Janice Eberly (2016) attribute part of the decline in investment to the relocation of capital-intensive manufacturing industries from the United States to other countries. It is particularly important that neither of these hypotheses is obviously related to the recession.

Although our account—like that of the Congressional Budget Office (2012)—leaves little room for demand-side explanations of persistently slow growth, we do investigate demand-side forces. Two quantitatively important factors are the unusually slow growth of federal government purchases from 2012 to 2014, which we associate in part with the 2013 U.S. federal budget sequester; and the delay in the usual rebounding of state and local government purchases, which we associate with the housing market collapse and the financial crisis. Absent such delays, output growth would have been higher early during the recovery. The solid line in the right panel of figure 1 would have intersected the dashed line sooner, implying less cumulative loss in output (and employment). However, looking over the entire recovery, the seeds of the disappointing growth in output were sown before the recession in the form of a declining labor force participation rate and slow TFP growth. Indeed, the scaling back of consumption and investment plans in response to slowing TFP growth could induce its own recessionary pressures beyond those from the financial crisis alone. Olivier Blanchard, Guido Lorenzoni, and Jean-Paul L’Huillier (2017) show that this effect could be large, especially with interest rates at the zero lower bound.

Turning now to the details of our analysis, we use counterfactual, cyclically adjusted paths that variables would have followed, absent the recession. We use two methods of cyclical adjustment. The first, which we use for the counterfactual output path in figure 1 , measures the cycle using the unemployment rate and adjusts the variables in the growth-accounting identity using a version of Okun's law. The second, which we use primarily for our analysis of sources of slow 
demand growth and the timing of the recovery, is conditioned instead on the state of the economy at the cyclical trough in 2009 to compute a baseline forecast from a dynamic factor model. The first method measures slow growth, relative to the recovery of the unemployment rate; the second measures slow growth, relative to a "normal recovery" forecast made at the trough. As discussed in section III, after adjusting for these differences, the two methods provide similar estimates of the growth decomposition, so our growth-accounting analysis focuses on the Okun's law method.

The Okun's law method implies that growth of business output per person during the recovery fell short of its average in the three earlier recoveries by 1.8 percentage points per year, cumulating in a total shortfall during the recovery of 13.5 percent. The TFP shortfall contributed nearly 1 percentage point per year, or 7 percentage points for the cumulative output shortfall. The participation shortfall accounted for 0.9 percentage point per year of the output shortfall, or 6.1 percentage points for the cumulative shortfall. The centrality of the decline in TFP growth and the fall in the labor force participation rate leads us to examine them in greater detail in sections IV and V.

TOTAL FACTOR PRODUCTIVITY Time series methods date the slowdown in cyclically adjusted TFP growth to before the recession. Regime-shift detection methods estimate a break date in early 2006. Alternative Bayesian estimates and standard low-pass filtering, neither of which assumes a sharp break, place the slowdown even earlier. The timing matters: If the slowdown in TFP growth occurred before the recession, the recession cannot be its cause.

In addition, weak investment and capital growth were not important independent contributors to weak output growth during this recovery. Actual investment was almost exactly in line with our simulated forecast at the beginning of the recovery. Furthermore, as noted above, by 2016, the capital-output ratio was in line with its long-term trend. As a result, the shortfall in labor productivity is almost entirely explained by weak TFP growth.

Given the importance for the recovery of the prerecession slowdown in TFP growth, we review a number of candidate explanations for the mid-2000s TFP slowdown and provide some new evidence against one, namely, changes in regulations. We lean toward the hypothesis that the 
slowdown reflects a slackening in the broad-based, transformative effects of information technology — a productivity boom that began in the mid-1990s and ended in the mid-2000s.

THE LABOR FORCE PARTICIPATION RATE In 2016, the labor force participation rate, at 62.7 percent, was 3 percentage points below its value at the trough. Although different methods for estimating the cyclical component of the participation rate provide different estimates of its cyclical decline early in the recovery, by 2016 that cyclical contribution was small.

Baby boom retirements are an important factor behind the decline in labor force participation. Less widely recognized is that other factors partially push the other way-notably the increasing education levels of the newly older workers. We construct an annual index that allows for shifting population shares in age, education, gender, and marital status. These demographic effects account for 0.6 percentage point of the overall decline of 1.8 percentage points from 2010 to 2016. Changes in participation rates within detailed demographic groups account for the remaining 1.2 percentage points, or nearly two-thirds of the decline.

There is no consensus about the sources of the persistent unexplained component of labor force participation. We argue that it is not plausibly just a consequence of the increase in unemployment during the 2007-09 recession. For example, the twin recessions of the early 1980s did not lead to comparable declines in participation relative to the trend. Our review of the evidence supports the less optimistic view that the nondemographic part of the decline represents a continuation of preexisting trends with a variety of sources that are likely to persist.

TIMING OF THE RECOVERY AND DEMAND CONSIDERATIONS In our story, the economy's underlying growth rate would have slowed sharply even without the deep recession. Nevertheless, it took some nine years from the beginning of the recession for the unemployment rate to return to normal. Deficient demand in the recovery (including from the zero lower bound) plausibly slowed the return to its sharply slowing trend. The dynamic factor model sheds light on the sources of deficient demand. As in our earlier analysis, we calculate a simulated forecast as of 2009 and study its subsequent errors. The errors are stated as percentage-point contributions to an overall forecast error of 0.57 percent of GDP per year, which is close to the Okun's law shortfall, after adjusting for slower trend growth and normal cyclical movements. 
Weak government spending restrained the expansion. The shortfall in government purchases explains more than half the forecast error ( 0.31 percentage point per year, of which 0.20 is federal and 0.12 state and local). Government consumption expenditures plus transfer payments would normally have grown by 2.9 percent per year, but in fact grew by only 0.7 percent.

Total household consumption-by far the largest component of total spending — contributed 0.26 percentage point per year to the shortfall in output growth. Durable and nondurable goods behaved almost exactly as forecasted during the expansion. Roughly half the shortfall arose from housing and financial services, which is consistent with the view that housing and finance were key sectors for explaining the special features of the recession and recovery. The real value of financial services, however, is a particularly poorly measured component of output. The shortfall in this sector, and in the even more poorly measured sector of nonprofit institutions serving households, contributes fully 0.10 percentage point to the 0.57 percentage point underforecasting of output. So a small part of the slow measured growth could be due to mismeasurement.

These forecasts suggest that there was little role for several weak demand explanations. The absence of any significant shortfall in consumption growth outside housing is evidence against deleveraging and increasing inequality contributing to the slow recovery. Weak exports exerted a small drag on output growth, mainly during the years 2011-13. And business investment was in line with forecasts,- - which is consistent with our view that business investment, a highly cyclical, endogenous variable, was not an exogenous contributor to the weakness of the recovery.

\section{Growth Decomposition and Data}

Subsection I.A describes our general objective and our data. Subsection I.B then lays out the Solow-style growth-accounting framework we use to analyze the slow recovery of output.

\section{I.A Focus and Data}

We focus on explaining the disappointingly slow recovery that started in mid-2009, which was when the recession ended, according to the National Bureau of Economic Research. We end seven years later, in mid-2016. When we make comparisons with the preceding three recoveries, we 
use the comparable seven-year periods following the troughs, except for the period following 2001, for which we truncate the business-cycle peak at the end of 2007 (six years).

The slow recovery of output can be examined through the lens of production (since output is produced) or expenditures (since output is purchased). Here, we discuss growth-accounting identities related to production. The production framework is natural for addressing the role of structural trends such as productivity and the labor force. We apply this accounting to the business sector. Growth accounting is less applicable to government, household, and nonprofit production, where output is often not measured independent of inputs.

Our measure of output is the geometric average of income- and expenditure-side measures, as recommended by Jeremy Nalewaik (2010) and subsequent literature—-see the online data appendix. Both sides of the accounts provide information about true growth but are subject to measurement error, so a combination improves the signal-to-noise ratio. At an economy-wide level, we follow the Council of Economic Advisers (2015) and refer to this average of GDP and gross domestic income as gross domestic output (GDO) or, where the context is clear, as simply output. Unless noted otherwise, we scale output by the population eligible for employment, age 16 years and above, denoted Pop.

John Fernald (2014) describes our quarterly business sector growth-accounting data. Broader output data come from the U.S. Bureau of Economic Analysis; additional labor market data come from the U.S. Bureau of Labor Statistics. The online data appendix provides further details.

\section{I.B Accounting for Growth}

Although our growth accounting focuses on the business sector, we also need to consider the overall economy because labor market indicators, such as the unemployment rate, are economy-wide. An identity links economy-wide GDO and business output, $Y_{t}^{\text {Bus }}$ :

$$
\left(\frac{G D O_{t}}{P_{o p_{t}}}\right)=\left(\frac{G D O_{t}}{Y_{t}^{\text {Bus }}}\right) \times\left(\frac{Y_{t}^{\text {Bus }}}{\operatorname{Pop}_{t}}\right)
$$

The identities in this section are sometimes expressed as ratios of levels and sometimes as growth rates, depending on which one is clearer. Empirical estimation is in growth rates. 
Growth accounting decomposes output growth into a set of components that help to show how the second term on the right-hand side of equation (1)evolves. Modern growth accounting follows Jorgenson and Zvi Griliches (1967), which in turn expanded and clarified the work of Robert Solow (1957). Growth in business output, $Y_{t}^{\text {Bus }}$, depends on growth in capital, $K$, and labor input, Labor. Labor, in turn, depends on Hours and labor quality, LQ:

$\Delta \log$ Labor $_{t}^{\text {Bus }}=\Delta \log L Q_{t}+\Delta \log$ Hours $_{t}^{\text {Bus }}$. Labor quality $L Q$ captures the contribution of rising education and experience. Our measure of $L Q$ assumes that relative wages capture relative productivities of workers with different attributes—see Bosler and others (2016). In per-person terms, we write:

$$
\Delta \log \left(\frac{Y_{t}^{\text {Bus }}}{\text { Pop }_{t}}\right)=\Delta \log \operatorname{TFP}_{t}+\alpha_{t} \Delta \log \left(\frac{K_{t}}{\text { Pop }_{t}}\right)+\left(1-\alpha_{t}\right) \Delta \log \left(\frac{L Q_{t} \cdot \text { Hours }_{t}^{\text {Bus }}}{\operatorname{Pop}_{t}}\right)
$$

The time series $\alpha_{t}$ is capital's share of income.

It is useful to rewrite equation (2) to separate endogenous and exogenous factors. For example, suppose hours growth falls because of demographics. Equation (2) multiplies that change by labor's share. But if the same force leads to an endogenous reduction in capital, we may want to incorporate this effect. We consider an alternative decomposition of $\left(Y_{t}^{\text {Bus }} / \mathrm{Pop}_{t}\right)$ as business sector hours per person times labor productivity (output per hour of work):

$$
\left(\frac{Y_{t}^{\text {Bus }}}{\operatorname{Pop}_{t}}\right)=\left(\frac{\operatorname{Hours}_{t}^{\text {Bus }}}{\operatorname{Pop}_{t}}\right)\left(\frac{Y_{t}^{\text {Bus }}}{\operatorname{Hours}_{t}^{\text {Bus }}}\right)
$$

The first term on the right-hand side, business hours per person can be expanded as:

$$
\left(\frac{\text { Hours }_{t}^{\text {Bus }}}{\text { Pop }_{t}}\right)=\left(\frac{\text { Hours }_{t}^{\text {Bus }}}{E_{m}^{\text {Bus }}}\right) \times\left(\frac{E m p_{t}^{\text {Bus }}}{E m p_{t}^{C P S}}\right) \times\left(\frac{\text { Emp }_{t}^{\text {CPS }}}{\text { LabForce }_{t}}\right) \times\left(\frac{\text { LabForce }_{t}}{\text { Pop }_{t}}\right)
$$

The terms on the right-hand side of equation (4) are as follows:

$$
\text { - }\left(\frac{\text { Hours }_{t}^{\text {Bus }}}{E_{m}^{\text {Bus }}}\right) \text { is business sector hours per employee. }
$$


- $\left(\frac{E m p_{t}^{\text {Bus }}}{E m p_{t}^{C P S}}\right)$ is the ratio of business employment, measured (primarily) from the establishment survey, to household employment, measured from the Current Population Survey (the household survey).

- $\left(\frac{E m p_{t}^{C P S}}{\text { LabForce }_{t}}\right)$ is employment relative to the labor force, and is by definition equal to $1-U_{t}$, where $U_{t}$ is the unemployment rate. Over the long run the contribution of the $U$ term is zero because the unemployment rate reverts to a mean value.

- $\left(\frac{\text { LabForce }_{t}}{\text { Pop }_{t}}\right)$ is the labor force participation rate.

Now consider labor productivity, the second term on the right-hand side of equation (3) With some manipulation, growth-accounting equation (2) yields the useful expression:

$$
\Delta \log \left(\frac{Y_{t}^{\text {Bus }}}{\text { Hours }_{t}^{\text {Bus }}}\right)=\frac{\Delta \log T F P}{\left(1-\alpha_{t}\right)}+\left(\frac{\alpha_{t}}{1-\alpha_{t}}\right) \cdot \Delta \log \left(\frac{K_{t}}{Y_{t}^{\text {Bus }}}\right)+\Delta \log L Q_{t} .
$$

In this expression, output per hour depends on the capital-output ratio, and labor quality, both expressed in labor-augmenting form. This is useful, because capital deepening is endogenous. Slower growth in technology and labor lead to a lower path of capital—but a roughly stable capital-output ratio. Thus, the capital-output ratio is useful for assessing whether there are special influences on capital from, say, unusual credit constraints or heightened uncertainty.

In the one-sector neoclassical growth model, the capital-output ratio is pinned down by an Euler equation. If trend technology were constant, the steady-state ratio would be stationary. In models with investment-specific technical change — and in the data — this ratio has a relatively slowmoving trend (see the online appendix to Fernald 2015).

Of course, the capital-output ratio is not necessarily dispositive. Slower trend growth tends to raise the steady-state capital-output ratio. Other factors, such as an increase in market power (Gutiérrez and Philippon 2016), could work in the other direction. Nevertheless, in cyclically adjusted data, the trend capital-output ratio has been remarkably smooth since the 1970s, despite the mid-1990s speedup in growth and the mid-2000s slowdown. Thus, we interpret the capital-output ratio as informative about the possibility of a capital shortfall. 


\section{Estimation of Cyclical Components and Low-Frequency Trends}

As the unemployment rate declines during an expansion, output grows faster than it would with constant unemployment. The deeper the recession, the greater is the recovery in the labor market and the greater is the cumulative above-normal growth of output. Thus, in determining whether the recovery from the 2007-09 recession was slow, we need to control for the depth of the recession. Moreover, the calculation needs to control for underlying systematic changes in the U.S. economy, such as changes in workforce demographics, that affect the underlying mean growth rates of employment and output.

In this paper, we use two complementary methods for controlling for the depth of the 200709 recession and thus for assessing the recovery's speed. The first method is conditioned on the path of the unemployment rate. This method asks: What would the normal cyclical path of output and the other variables in the growth decomposition have been, given the 2009-16 recovery of the unemployment rate? In practice, this amounts to estimating the normal cyclical movements using Okun's law, extended to variables in addition to output.

The second method controls for the depth of the recession by conditioning on the state of the economy at the 2009 trough, as measured by a large number of time series. This method asks: What would the normal, cyclical path of macroeconomic variables have been, given the depth of the recession? Calculating the normal path entails simulating forecasts of multiple time series, given data through 2009, for which we use a large dynamic factor model.

Both methods allow for low-frequency changes in the mean growth rates, that is, for trends in the growth rates. We adopt a statistical decomposition of the growth rate of a given time series into a trend, a cycle, and an irregular part. Let be the percentage growth rate of a variable at an annual rate, computed using logs (for example, for GDO, $y_{t}=400 \Delta \log G D O_{t}$ ). The decomposition is,

$$
y_{t}=\mu_{t}+c_{t}+z_{t}
$$

where $\mu_{t}$ is a long-term trend, $c_{t}$ is a cyclical part, and $z_{t}$ is called the irregular part-it describes the higher-frequency movements of the variable that are not correlated with the cycle.

Following convention in the time series literature, we refer to equation (6) as a trend/cycle/irregular decomposition. Because $y_{t}$ is a growth rate, the trend $\mu_{t}$ is the long-term mean 
growth rate of the series. In the special case that this mean is constant, in log-levels the series would have a linear time trend, with a shifting intercept that depends on $c_{t}$ and $z_{t}$. As explained below, we estimate the long-term trend as the long-run average of $y$, after subtracting the cyclical part. This long-run average typically evolves for reasons such as changing demographics.

The irregular term, $z_{t}$, is the variation in $y_{t}$ net of the trend and cyclical fluctuations. This irregular term represents the growth in a given variable, above and beyond what would be expected given low-frequency changes in the economy and the normal cyclical movements. We find that large, negative, irregular parts play important roles in the weak recovery.

\section{II.A Method 1: Using Okun's Law to Account for the Cycle}

The first method uses Okun's law to estimate the cyclical component. Because we consider many series, and these series can lead or lag the unemployment rate, we extend Okun's relationship to include leads and lags. The Okun's law definition of $c_{t}$ thus is,

$$
c_{t}=\sum_{j=-p}^{q} \beta_{j} \Delta U_{t+j}=\beta(\mathrm{L}) \Delta U_{t},
$$

where $U_{t}$ is the unemployment rate and $\beta(\mathrm{L})$ is the distributed lag polynomial with $q$ leads and $p$ lags in the summation. The choices of $p$ and $q$ and other estimation details are described in the next subsection. The sum of the lag coefficients, $\beta(1)$, measures the cyclical variability of $y_{t}$. Note that because $E \Delta U_{t}=0$ over the long run, our cyclical part has a long-run mean of zero.

Okun's original relationship was the reverse of equation (7), regressing changes in the unemployment rate on changes in output with only contemporaneous movements. However, subsequent researchers have often used the specification with unemployment on the right-hand side. Moreover, for output growth and many other series, the leads or lags are statistically significant. Daly et al. (2017) discuss growth-accounting foundations of Okun's Law and assess its stability over time.

Also, though one could add other measures of labor market slack to equation (7), using the standard unemployment rate (as we do) has several virtues. It is well measured, and it has been measured using essentially the same survey instrument since 1948. Over the long run, it has essentially no trend. And, in any event, the other measures of the state of the labor force are highly correlated with the unemployment rate, once one incorporates leads and lags. 
THE CYCLICALLY ADJUSTED TREND A practical problem in estimating the trend $\mu_{t}$ is that persistent cyclical swings can be confused with lower frequency trends. This problem is particularly acute in estimating trend terms toward the end of our sample, given the severity of the recession and length of the recovery. To address this problem, our estimate of the trend controls for the normal cyclical movements implied by Okun’s law.

Substitution of equation (7) into equation (6) yields

$$
y_{t}=\mu_{t}+\beta(\mathrm{L}) \Delta U_{t}+z_{t}
$$

The Okun's law “residual” (including $\mu_{t}$ ), $y_{t}-c_{t}=y_{t}-\beta(\mathrm{L}) \Delta U_{t}$ is a measure of what the growth rate would have been, consistent with an unchanged unemployment rate. To estimate $\mu_{t}$, we adopt the framework of the partial linear regression model, which treats $\mu_{t}$ as a nonrandom smooth function of t/T; see Peter Robinson (1988), James Stock (1989), and Ting Zhang and Wei Biao Wu (2012). In this approach, $\mu$ is estimated as a long-run, smoothed value of $y$, after subtracting the estimated cyclical part:

$$
\hat{\mu}_{t}=\kappa(\mathrm{L})\left(y_{t}-\hat{\beta}(\mathrm{L}) \Delta u_{t}\right)
$$

where $\kappa(\mathrm{L})$ is a filter that passes lower frequencies and attenuates higher frequencies. Because the estimated cyclical part is subtracted before smoothing, we refer to the estimated trend $\hat{\mu}_{t}$ as a cyclically adjusted trend. The use of a cyclically adjusted trend with a long bandwidth for $\kappa(\mathrm{L})$ helps avoid mechanically attributing the recent slow growth to a declining trend. The online appendix compares the partial linear regression approach to Robert Gordon's (2014) cyclically adjusted state space (unobserved components) method, and discusses computation of the heteroskedasticity- and autocorrelation-robust standard errors.

ESTIMATION We estimate $\beta(\mathrm{L})$ by regressing $y_{t}$ on leads and lags of $\Delta U_{t}$ with $p=q=2$. For some left-hand-side variables, using only contemporaneous $\Delta U_{t}$ suffices; but for others, additional leads and lags are justified statistically. Our estimation period starts at the 1981 peak and ends in the second quarter of 2016. Sensitivity to these choices is discussed below.

For the low-pass filter,$\kappa(\mathrm{L})$, we use a biweight filter with truncation parameter of 60 quarters. Tukey's biweight filter $\kappa(\mathrm{L})$ is two-sided, with $\kappa_{j}=d\left(1-(j / B)^{2}\right)^{2}$ for $|j| \leq B$ and $=0$ 
otherwise, where $B$ is the bandwidth and $d$ is chosen so that $\kappa(1)=1$. End points are handled by truncating the filter outside the range of the data and renormalizing. The long truncation parameter was chosen so that changes in $\hat{\mu}_{t}$ reflect slow multidecadal swings. If there are sharp breaks, this filter will oversmooth, an issue to which we return in section IV.

ADDITIVITY The foregoing method for estimating the trend, cycle, and irregular parts has the useful property of preserving additivity when applied to additive decompositions. Specifically, suppose that $y_{t}=y_{1 t}+y_{2 t}$. This additivity is preserved for the estimated cyclical, trend, and irregular parts. That is, $\hat{\mu}_{t}=\hat{\mu}_{1 t}+\hat{\mu}_{2 t}$ and $\hat{c}_{t}=\hat{c}_{1 t}+\hat{c}_{2 t}$, where the subscripts refer to the parts of $y_{t}, y_{1 t}$, and $y_{2 t}$. This property is a consequence of using the same cyclical regressors and same filter $\kappa(\mathrm{L})$ for all series, and the property that regression is linear in the dependent variable.

\section{II.B Method 2: Dynamic Factor Model Estimates of the Cycle}

The second method uses a six-factor, dynamic factor model to produce forecasts of the variables under study, where the forecasts are made using data through the 2009 trough. These projections provide an alternative estimate of the cyclical component-specifically, the normal cyclical rebound that would have been expected given the depth of the recession.

The 123 series used to estimate the factor are summarized in table 1. The data set omits highlevel aggregates to avoid aggregation identities and double-counting-for example, GDP is omitted because its components are included; consumption of goods are omitted because the consumption of durables and nondurables are included separately; and total employment is omitted because its components are included. The 123 series are transformed into growth rates (for activity variables; see the online appendix for the details of other series); low frequency trends are extracted, as discussed above; and six factors are then estimated using principal components.

These six factors are forecasted through the second quarter of 2016 using a vector autoregression with four lags, with the 2009 trough as the jumping-off point. Forecasts for a given variable are then computed using the factor loadings from a regression of that variable on the factors. The forecasting regressions are estimated using data from 1984 through the 2009 trough. 
Stock and Mark Watson (2016) discuss factor methods and provide empirical results for closely related models and data sets. The online appendix has additional details, including measures of fit.

With one exception, the simulated forecasting approach freezes the growth rate trends in each series at their trough values. The exception is that we allow demographic changes to affect labor force participation. It was clear before the recession that baby boomers' retirements would depress participation. Here, we use the Divisia-Törnqvist index — developed in section V—to project the effect of changing demographics. This demographic trend in participation feeds through, with share weights as appropriate, into the trends in employment, hours, and output. We leave unchanged the trends in capital, the ratio of business to household employment, and hours per employee. The result is a projected output trend that incorporates aging and other demographic effects on employment as understood at the trough, with other component trend growth rates frozen at their trough values. Trend growth rates for expenditure components of output are computed as the component's time series trend as of the trough, plus the share-weighted difference between the output trend (inclusive of the participation aging trend) and the trough value of the output trend. This final adjustment, which ensures that share-weighted trend growth rates are additive, is numerically negligible because the trough-quarter participation adjustment to the trend value of output is small.

In the notation of equation (6), the factor model forecast of $y_{t}$ is the sum of the trend projection $\mu_{t}$ and the projection of $c_{t}$ computed using the detrended factors. Thus, the forecast error is an estimate of the irregular part; subtracting this forecast error measures the growth shortfall of $y$.

The dynamic factor model method, like the Okun method, preserves the additivity of the components.

\section{Results: Accounting for Slow Growth}

We are now ready to quantify the sources, in a growth-accounting sense, of the slow growth in output. We begin with a brief discussion of the cyclical properties of the component variables in the growth-accounting decomposition. 


\section{III.A Cyclical Properties of the Growth-Decomposition Variables}

Table 2 provides three summary measures of the cyclicality of the variables entering the growth decomposition and additional broad measures of output. The first column shows the generalized Okun's law coefficient, which provides a natural measure of cyclicality. Specifically, it is the sum of the coefficients, $\beta(1)$, in equation (8); the units are chosen so that the coefficient is the percent change in each variable per percentage point change in the unemployment rate. The sum of the Okun's law coefficients on the components equals the Okun's law coefficient on the sum of the components. For example, the coefficients in lines 7 through 9 add to -2.02 , which is the coefficient in line 6 for real business output per capita.

Of the total cyclical variation in business hours per capita (line 10), as measured by the generalized Okun's law coefficient of -2.3 , nearly half $(-1.08)$ comes from the employment rate (1 minus the unemployment rate), one-sixth $(-0.35)$ comes from variations in hours per worker, and a small amount (-0.16) comes from labor force participation. These results reflect the small procyclicality of the participation rate, which falls as unemployment rises. Of course, a large reduction in participation occurred before and during the recovery. Section V examines the extent to which the recent decline in participation is related to the slack labor market.

One-third of the cyclical variation in business output $(-0.71)$ comes from procyclical variation in the ratio of business employment to household survey employment. Differences in coverage and concept help explain this variation. In terms of coverage, the household survey is broader, covering the entire civilian economy; and the business sector is much more procyclical than the nonbusiness sector (for example, government and nonprofits). In terms of concept, a worker holding two jobs counts twice in the establishment survey but just once in the household survey. If this worker loses one of these jobs when the unemployment rate rises, then establishment survey employment falls more than household survey employment. After adjusting for coverage, Fernald and Christina Wang (2016) find that hours worked—number of workers times hours per worker-has almost the same cyclicality in the two surveys.

Labor productivity (line 15) is weakly and insignificantly countercyclical. It combines strongly procyclical TFP (line 7 or, rescaled, line 16) with the strongly countercyclical capital-output 
ratio (line 17). Research on TFP has discussed the roles of labor hoarding, cyclical changes in capital utilization, and other nontechnological factors that account for the procyclicality of productivity (Basu and Fernald 2001). Investment is procyclical, but the cumulated stock of capital changes only slowly; so the capital-output ratio is strongly countercyclical because of output in the denominator. Finally, the countercyclicality of labor quality (0.13, row 18) supports the hypothesis that when unemployment rises, lower-skilled workers differentially become unemployed.

The remaining columns of table 2 quantify the variation in each variable that is cyclical, as measured first by the standard deviation of the Okun's law estimate of $c_{t}$ and second by the fraction of the variance of the series explained by the factors (that is, the $R^{2}$ of the common component in the dynamic factor model). By both measures, the most cyclical variable is the employment rate—by construction, for the Okun's law estimate; and as a result of the factors explaining variation in employment, for the factor model estimate. Although cyclical variation in TFP accounts for onefourth of the cyclical variation in business output per capita, cyclical variation only accounts for a fraction of the variation in TFP growth. TFP growth has a large amount of high-frequency variation, including measurement noise.

\section{III.B Growth Components: Trend and Cyclical Parts}

Table 3 summarizes the results of the growth-accounting decomposition, where Okun’s law is used to estimate the cyclical component conditional on the unemployment rate path. The table compares the mean values of these components in the recent recovery with their mean values in the three previous recoveries. For this table, the three previous recoveries are defined as the first 28 quarters of the recovery (the number of quarters from the first one after the trough to the end of our sample) or the trough-to-peak period, whichever is shorter. Columns a, b, and c in table 3 present actual average historical growth rates, and contributions to growth rates, at annual rates. Columns d, e, and f provide the decomposition after cyclically adjusting these variables using the Okun's law method.

Figures 3, 4, and 5 show (with the solid linesin black) the log levels of the series in table 3 These figures also plot the cyclically adjusted series, using Okun's law (the dotted lines in red), and the cyclically adjusted trend (the dashed blue line). The solid and dotted lines in the right panel of 
figure 1and in the top-left panel of figure 3 are the same, but with different time scales and normalizations (see the figure notes).

Table 4 is the counterpart of table 3, in which the cyclical component is computed using the factor-based method, conditional on the state of the economy in mid-2009. The first column, the forecast, is the sum of the cyclical component of the forecast and the trend, averaged over the 200916 forecasting period. The second column is the actual average growth of the variable, and the third column is the factor estimate of the irregular part, $z$, which is the shortfall — that is, the gap between forecasted and actual growth. The standard error of the cyclical component (that is, of the common component of the dynamic factor model) is given in parentheses. ${ }^{1}$

\section{III.C Components of Expenditure: Trend and Cyclical Parts}

Many proposed explanations for the slow recovery appeal to deficient demand or to deficiency in a component of demand. To shed light on these explanations, we undertake the same trend/cyclical/irregular decomposition for variables in the GDP expenditure identity.

Table 5 shows these decompositions using (share-weighted) contributions to growth. The first column of numbers shows the average growth contributions from 2009 to 2016. Because the forecasts and forecast errors are additive, the trend values, forecasts, and forecast errors in the remaining columns also add to their respective aggregates. The second block of columns presents results using the Okun's law cyclical adjustment, and the final block presents results using the dynamic factor model; the shortfall is the negative of the forecast error.

Figure 6 presents plots of selected dynamic factor model forecasts, their actual value, and their trend. For these plots, series that appear as components in tables 4 and 5 are not share-weighted. Plots for all the variables presented in tables 4 and 5 are given in the online appendix.

\footnotetext{
${ }^{1}$ The shortfall in the third column is the negative of the usual definition of a forecast error. In addition, the standard error of the conditional mean in the fourth column is not the forecast standard error (which incorporates uncertainty associated with future values of the factors and shocks), but rather is the sampling standard error arising from estimating the vector autoregression and other regression coefficients.
} 


\section{III.D Discussion}

A key difference between our two methods concerns the counterfactual cyclical path of labor market variables. The Okun method is conditioned on the unemployment rate path; thus, by construction, there is no irregular part for the unemployment rate, and the irregular part for closely related labor market variables is small. In contrast, the forecasting exercise projects a normal cyclical path for all the variables, conditional on the state of the economy at the trough in 2009; in principle, the actual path of any variable, including labor market variables, can depart arbitrarily from its forecasted path. The factor forecasts capture two key features of the recovery, in that they underpredict the labor market recovery and overpredict output growth. We return to this and other implications of the factor forecasts at the end of this section.

Aside from this major difference in forecasts of output and unemployment in the recovery, the two methods generally yield quantitatively similar estimates of the irregular part, and lead to similar conclusions about the behavior of the components of output growth during the recovery. For clarity, we therefore focus primarily on results using the Okun method.

We begin with the first group of columns in table 3, which summarizes the shortfall of output and the growth decomposition components without cyclical adjustment. GDO grew 3.57 percent per year in the previous three recoveries (column a), but only 2.20 percent in the current recovery (column b), for a shortfall of 1.37 percentage points (column c). Similarly, business output per capita grew 2.92 percent in the previous three recoveries, but only 1.72 percent per year in the current one, for a shortfall of 1.21 percentage points. Looking down column c, many of the rows are nonzero, but a few stand out. These include a decline in the growth of capital per person (capital shallowing, row 8), a decline in the growth rate in TFP (rows 7 and 16), and a decline in the labor force participation rate (row 14).

This comparison of actual growth rates understates the output shortfall, however, because it does not account for how deep the recent recession was relative to the three previous ones on average. The second group of estimates presents the same decomposition after removing the cyclical component using Okun's law-that is, conditioning on the unemployment rate. 
This cyclical adjustment creates a different, starker picture of the slow growth situation. The shortfall in business output per person is much larger, at 1.81 percentage points, reflecting the depth of the 2007-09 recession. The cumulative shortfall in output is 13.5 percent (final column). After cyclical adjustment, the only element that is quantitatively important for explaining hours is labor force participation (row 14), and the only element that is quantitatively important for labor productivity is TFP (row 16). Shortfalls in the direct contribution of capital input per person are also large (row 8), but when scaled by output (row 17) the contribution is small.

We now discuss selected elements of the growth accounting.

BUSINESS OUTPUT Figure 3 above, which shows the cumulative parts of the growth of business output per capital, conveys a basic finding of this paper. For the period of the recovery from the crisis recession, the consistent improvement in the labor market should have been associated with a dramatic recovery of output, based on historical, cyclical patterns. But two powerful forces opposed the cyclical part: the low-frequency trend and the high-frequency irregular part. Moreover, the downward slopes of the two parts are almost the same, and our breakdown of the noncyclical behavior of output gives equal roles to the high- and low-frequency parts.

HOURS PER WORKER Figure 4 above shows the levels of the three statistical parts of weekly hours per worker. Consistent with the coefficient of -0.35 given in table 2 , the cyclical part of hours rose smoothly during the recovery, as in the three earlier recoveries. The slope of the lowfrequency trend plotted in the figure, $\mu_{t}$, rose slightly, though the high-frequency irregular part fell slightly. Unlike many other indicators, weekly hours behaved fairly normally in the postcrisis recession.

LABOR FORCE PARTICIPATION Figure 4 shows that the low-frequency trend in participation grew at a declining rate until 1998, and then began to shrink. The rate of shrinkage declined slightly in the last years shown. The cyclical part grew during the recovery, but both the high- and low-frequency parts declined. The net effect was a substantial decline in labor force participation during the recovery, in contrast to the pattern of low but positive growth in recoveries through the 1990s. Section V pursues explanations of the labor force's recent anomalous behavior. 
LABOR QUALITY Although labor quality contributes to low-frequency growth in productivity (figure 5), it explains little of the post-2009 cyclically adjusted growth shortfall.

CAPITAL INPUT At first glance, capital input table 3, row 8) appears to contribute a moderate amount to the shortfall in output. However, as we noted above, capital input is jointly determined with TFP, the labor force, employment, and other endogenous variables. Row 17 of table 3 shows that when measured relative to output, there was essentially no shortfall in the cyclically adjusted growth rate of capital. Figure 5 shows that the low-frequency part, and to a lesser extent the high-frequency part, started to decline somewhat before the crisis.

SENSITIVITY ANALYSIS In the online appendix, we report results for table 3 estimated using different numbers of lags in the Okun's law equation (8), and using different estimation samples. Most of the Okun's law coefficients in table 2-including the headline coefficients on GDP, GDO, and business output-are insensitive to these changes. For the labor force participation rate, the generalized Okun's coefficient increases from -0.16 to -0.37 when 12 lags are used, but using 12 lags somewhat reduces this coefficient for TFP. It is particularly important that the overall cyclically adjusted shortfall is quite robust to these changes, as is our decomposition. The reason for this robustness is that although the Okun's law coefficients change somewhat for some series, by mid2016 the decline in the unemployment rate had slowed down as the economy approached full employment, so the net cyclically adjusted contributions did not change substantially.

COMPARING THE OKUN'S LAW AND FACTOR MODEL ESTIMATES Table 4 shows that compared with what would have been expected based on the data through 2009, actual GDP growth fell short by 0.57 percentage point, GDO growth fell short by 0.43 percentage point, and business output fell short by 0.35 percentage point. These cyclically adjusted shortfalls are smaller than their counterparts in table 3 because the recovery of employment was stronger than expected based on the factor forecasts: The Okun's law method in table 3 is conditioned on the unemployment rate path, but the factor model forecast has a shortfall in the household employment rate of -0.42 ; that is, the factor model predicts a less rapid fall in the unemployment rate. This feature of the factor forecasts - an unexpectedly strong recovery of the labor market, and an unexpectedly weak recovery of output-is consistent with the real-time errors of professional forecasters given in Figure 2. As a 
back-of-the-envelope comparison, using the per capita business output shortfall from the factor model of 0.27 percentage point, the negative shortfall in the employment rate of 0.42 , and the Okun's law coefficient of 2.02 for business output per capita yields an adjusted estimate of $1.12=(2.02 \times$ $0.42+0.27$ ) of the shortfall in business output per capita from the factor model, adjusted for the fact that the factor model underpredicts employment. This is roughly comparable to the 0.91 sum of the irregular component computed using Okun's law (0.63) plus the error forecasting the trend growth rate. As another example, though the factor model overpredicts the average growth rate of the capital-output ratio (see table 4), this ratio is countercyclical, and its growth rate exceeds the factor model forecast after adjustment for the forecast error in employment.

In summary, this section documents that slow growth since 2009 is essentially entirely accounted for by slow TFP growth and declining labor force participation. The crucial issue for interpreting these results is the extent to which the slowdown in TFP and the fall of participation were independent of or, alternatively, a consequence of the recession and its aftermath.

\section{Why Have Capital Accumulation and Productivity Fallen Short?}

Why has cyclically adjusted productivity growth been slow, and, relatedly, has there has been an unusual shortfall in capital deepening? We reach two conclusions.

First, according to both aggregate and industry-level data, the decline in productivity occurred before the recession. This observation strongly suggests that the recession was not the cause of the slowdown in cyclically adjusted productivity growth. Upon considering several candidate explanations for the productivity slowdown, including mismeasurement and an increasing regulatory burden, we are left to conclude that productivity growth slowed after the early 2000s because of a pause in or an end to the broad-based, transformative effects of information technology.

Second, weak capital formation was not an important independent contributor to weak output growth. Although investment was low during this recovery relative to earlier recoveries, capital growth was not low relative to output growth: By 2016, the capital-output ratio was in line with its long-term trend. If investment had been as strong as in the three earlier recoveries, the capital-output ratio would have grown by an improbably large amount. Using this ratio as the benchmark recognizes that businesses acquire capital to produce output. A long line of research using the 
investment accelerator recognizes this principle. This output benchmark inherently incorporates the fall of the underlying growth rate of output from the decline in cyclically adjusted productivity growth and the decline in labor force participation.

\section{IV.A When Did Productivity Growth Slow?}

Even before the financial crisis, professional forecasters had noticeably lowered their estimates of the trend in the growth of labor productivity. Figure 7 plots the median forecasts from the Survey of Professional Forecasters for productivity growth over the next 10 years. The forecasts broadly track the lagging 10-year average growth of actual labor productivity computed using both real-time and final revised data. Forecasts rose sharply between 1999 and 2000. They remained close to 2.5 percent through the 2006 survey. They have since fallen by about a percentage point. Half that decline occurred before the financial crisis, between 2006 and early 2008.

The slowdown is also evident in the time series data on TFP. Figure The top left panel of figure 5 shows that TFP growth picked up in the mid-1990s and slowed before the recession. The statistical question is whether those were persistent changes in trend growth, or more transient variations.

We undertake two sets of analyses of the timing and persistence of the slowdown in productivity growth. The first entails computing tests for a break or for a slower time variation in the mean of cyclically adjusted productivity growth. The second provides Bayes posterior inference on whether the decline in the mean occurred before the 2007-09 recession began.

Table 6 summarizes five tests for the null hypothesis that there is no time variation in the mean growth rate of TFP. Let $y_{t}^{c a}$ denote the cyclically adjusted growth rate of productivity, so that, following equation (6), $y_{t}^{c a}=\mu_{t}+z_{t}$, where $\mu_{t}$ is the local mean (or trend) value of $y_{t}^{c a}$, and $z_{t}$ is the mean-zero irregular component. Table 6 shows results for two sample periods: the 35-year sample from 1981 through 2016 that has been the primary focus of this paper; and, to increase power, a 60year sample from 1956 through 2016. The first three tests are the sup-Wald (the autocorrelationrobust Quandt likelihood ratio) break test of a constant mean against the alternative of, respectively, one, two, or three breaks. Along with the test statistic, this test yields estimates of the break dates 
themselves. The remaining two tests are the Nyblom (1989) tests that focus power on a small martingale variation in $\mu_{t}$, and the low-frequency stationary test (Müller and Watson 2008), a lowfrequency point-optimal test for a martingale variation.

All five tests reject the null hypothesis that is constant using the 1956-2016 sample, but not using the shorter-duration 1981-2016 sample. This primarily reflects the inclusion of the early-1970s productivity slowdown in the longer sample. The three-break, full-sample test identifies break dates in 1973, 1995, and 2006, with a $p$ value (for the null of no breaks) of 0.01 , which accords with the conventional view of a high-growth period before 1973; a lower-growth period until 1995; and the high-growth period of the technology boom. Notably, for our purposes the test does not find a break during or after the 2007-09 recession.

To gain additional insight into possible persistent changes in cyclically adjusted productivity growth, we use a latent variable state-space model for the trend and irregular components $\mu_{t}$ and $z_{t}$, in which $\mu_{t}$ is modeled as a Gaussian random walk and $z_{t}$ is modeled as Gaussian white noise. By adopting a Bayesian framework, we are able to undertake posterior inference on the timing of a peak in trend productivity growth and the magnitude of its decline before the recession. Details are given in the online appendix.

The results are summarized in figures 8 and 9. Figure 8 shows the four-quarter growth rate of cyclically adjusted TFP growth and three different estimates of $\mu_{t}$ : the cyclically adjusted biweight estimate (equation(9)), the three-regime estimate, with estimated break dates in 1995 and 2006; and a 67 percent posterior interval for $\mu_{t}$, from the Bayesian implementation of the random walk plus noise model. Figure 9 provides the posterior distribution of the date of the maximum of the local mean of productivity growth between 1981 and 2016.

Taken together, we interpret table 6 and figures 8 and 9 as providing coherent evidence that the decline in productivity growth started before the recession. The posterior distribution in figure 9 dates the peak of $\mu_{t}$ in the late 1990s or early 2000s, with little of the mass after 2006. The frequentist tests do not provide strong evidence of a break post-1981; but to the extent that they do suggest breaks, they occurred before the 2007-09 recession. Using the Bayesian approach, we can compute the posterior probability of the magnitude of the decline between the peak of $\mu_{t}$ in about 2000 and its 
value in 2007; this calculation yields a posterior median estimate of 0.72 percentage point using the full sample, and a 67 percent posterior interval of $(0.32,1.27)$. These estimates, which suggest a significant decline before the cyclical peak, are also consistent with the decline in the biweight estimate and the Bayes posterior sets shown in figure 8.

The discussion above focuses on measured TFP growth. A complementary perspective comes from looking at inputs to innovation, where a change in the trend is apparent in about 2000-even earlier than for productivity. Productivity grows as the economy accumulates better ways to produce output. The national accounts measure some investments in innovation—namely, in intellectual property products, which include software; research-and-development spending by businesses, universities, and nonprofits; and the production of books, movies, television shows, and music. Investment in these products grew at an annual rate of 8.1 percent from 1975 to 2000. After the tech collapse in 2000, that high growth rate slowed precipitously to only 3.5 percent from 2000 to 2007, close to its post-2007 pace of 3 percent. Recent research adds additional intangible investments in innovation, training, reorganizations, and the like. Estimates of these additional intangible investments by Carol Corrado and Kirsten Jäger (2015) also show a slower pace of growth after 2000.

In sum, in the U.S. data since the early 1970s, the unusual period for productivity growth was roughly the 10 years from 1995 to 2005, when growth was faster than before or since. Measured spending on innovation also shows a slowdown much earlier than the recession.

\section{IV.B Why Has Capital Fallen Short?}

On its face, concerns about weak investment seem appropriate; after cyclical adjustment, nonresidential investment growth contributed 0.47 percentage point to GDP growth during the previous three recessions, but only 0.13 percentage point during the recent recovery (table 5 ). This apparent shortfall in capital formation could reflect special features of the recession and recoverysuch as tighter credit, increased financial frictions, and heightened uncertainty; potential longer-term factors include heightened regulatory barriers, increased market power, and shifts in industry composition. 
Explaining this apparent shortfall requires a model of capital formation. The core of such a model is a demand function for productive capacity, which in turn depends on demand for output as well as the cost of capital. Jorgenson (1963) refined the principle by deriving the capital demand function from business optimization, conditional on the level of output and proportional to output. James Tobin (1969) refined the theory by incorporating adjustment costs.

Capital demand theory suggests benchmarks that would allow us to diagnose the role of special crisis-recession factors. Line 8 of table 3 shows that using only population as a benchmarkin effect, treating investment as exogenous_-implies a substantial capital/population shortfall in the recent recovery compared with the three earlier recoveries. However, line 17 of table 3 and the bottom right panel of figure 5 show that using output as the benchmark reverses the impression of a shortfall — the capital-output ratio in the recent recovery behaved in line with its average in the earlier recoveries. According to the output benchmark, the shortfall in investment is the natural companion of the shortfall in output. Investment theory assigns a major role to the demand for output as a driver of capital demand and therefore of investment.

Investment theory does include other determinants along with output. One is the return to capital, a measure that Jorgenson (1963) brought into formal investment theory. An important determinant of business investment is the payoff to owners of capital. Some accounts of weak investment imply that capital was not earning as much as in normal times. Others imply that the return would be above normal, because a force limiting investment resulted in extra profitability for the smaller amount of capital. But, as figure 10 shows, the earnings of capital—measured as the sum of business profits, interest paid, and depreciation — have been remarkably steady since the crisis. Earnings per \$1 of capital fell in 2009, but rebounded to normal in 2010 and have remained normal since then. The behavior of the return to capital supports our finding that investment was behaving normally, given the shortfall in output.

Gutiérrez and Philippon (2017) use Tobin’s (1969) q theory of adjustment cost to provide a benchmark. The variable $q$, a normalized measure of the value of firms recorded in the stock and bond markets, has risen to high levels during the recovery. So why has investment not been stronger? Jorgenson's optimization model implies that firms invest until the marginal revenue product of 
capital equals its rental price. Gutiérrez and Philippon cite evidence such as rising concentration ratios to argue that rising market power has increased the gap between average and marginal revenue products. Market power rationalizes weak investment with a strong stock market.

Gutiérrez and Philippon (2017) consider only the relation with adjustment cost (Tobin’s q), not the investment function. In the investment- $q$ plane, the $q$ equation slopes upward (the "supply" of investment), the function for demand for investment slopes down, and their intersection determines investment and the value of $q$. An increase in market power shifts the $q$ equation to the left, riding up the demand function, with lower investment and a higher value of $q$. Higher market power would reduce the capital-output ratio.

Alexander and Eberly (2016) find a shortfall in plant and equipment investment relative to a standard investment model. But the shortfall began in 2000, long before the recession of 2007-09, so their work supports our view that the capital-output ratio was not depressed by the recession itself. They attribute the shortfall to a shift toward investment in intellectual property and other intangibles. In manufacturing, firms tend to relocate physical production and its associated capital offshore, while retaining the intellectual property in the United States. Our measure of capital includes (some) intangible capital, so our finding of stability of capital input relative to output is consistent with Alexander and Eberly’s (2016) findings.

The stability of the capital-output ratio is not conclusive evidence that there was no shortfall in capital resulting from the recession itself. Productivity growth has been low, and the labor force participation rate fell, so the trend in output growth fell. Accordingly, the capital-output ratio should have risen, according to standard growth theory. But because, in fact, it did not rise, there has been a shortfall in the ratio. Conversely, rising market power would be a source of a decline in the ratio. It is beyond the scope of this paper to sort out quantitatively which effect dominates for the capital-output ratio. Our empirical evidence that the ratio is on its previous trend is consistent with the two forces roughly offsetting each other. In any case, in terms of investment, they point in the same directionthe level of investment itself should, at least for a time, be unusually weak for reasons unrelated to the recession or slow recovery, but rather because of lower productivity growth, declining participation, and possibly rising market power. 


\section{IV.C Explanations for Slow Productivity Growth}

Why has productivity growth been so slow if it is not the result of the financial crisis? Our conclusion is that the slowdown is plausibly a pause in—if not an end to- the information technology revolution. Our related conclusion is that the slowdown was not mainly the result of the recession. In this subsection, we review several hypotheses about the productivity slowdown. We begin with three nonrecession explanations and then return to the recession story.

1. MISMEASUREMENT Perhaps the problem of slow growth in both productivity and output is illusory. Plausibly, we could have missed many of the gains of from technology-related hardware, software, and digital services. But for mismeasurement to explain the productivity slowdown and its timing, growth must be mismeasured by more since the recession than in the previous 10 years.

Neither David Byrne, Fernald, and Marshall Reinsdorf (2016) nor Chad Syverson (2016) find evidence that, on balance, the mismeasurement of technology-related real output growth has in fact worsened since the early 2000s. In addition, the steady shift of economic activity toward poorly measured, slow-productivity-growth services, such as health care, does not change the picture, since the mid-2000s slowdown in productivity growth spread broadly across industries. Hence, changes in weighting matters relatively little. Philippe Aghion and others (2017) find a modest increase since the early 2000s in missing growth from creative destruction and increases in varieties. But the increase in bias is small relative to the measured slowdown in productivity growth.

2. RISING REGULATION AND THE LOSS OF DYNAMISM A rising regulatory burden could have slowed productivity growth (Barro 2016), and differing regulatory barriers do seem to matter across countries (Fatás 2016; Cette, Fernald, and Mojon 2016). Indeed, regulation could be a reason why, by many measures, the U.S. economy’s dynamism has declined over time (Decker and others 2016a, 2016b). Job creation and destruction have slowed; the business startup rate has fallen; and young firms have grown less in recent years. Ryan Decker and others (2016b) suggest that the character of declining dynamism changed after 2000, which would match the view that there were structural shifts in trend growth independent of the 2007-09 recession. This lack of dynamism could be a symptom of a lack of available or exploitable ideas. But some observers assert that its source is regulatory burdens, so we examine the regulatory-productivity link. 
In the United States, a rising federal regulatory burden does not appear to explain the medium-frequency variations in productivity. First, although some commentators have pointed specifically to post-2008 federal regulatory changes, the timing does not fit because the peak in productivity growth occurred before that time.

Second, even for the post-2008 period, the industries where regulation increased the most did not for the most part show a decline in productivity growth. Omar Al-Ubaydli and Patrick McLaughlin (2015) apply text-analysis methods to the U.S. Code of Federal Regulations to construct industry-level indexes of regulations from 1970 through 2014. Their RegData database covers 42 private industries that match industries for which we have productivity data from the U.S. Bureau of Labor Statistics for 1987 through 2014. (The online appendix describes the data in detail.) Industries with substantial increases in regulation after 2008 include, most notably (i) finance, (ii) energy (pipelines, oil and natural gas extraction, and utilities), (iii) construction, and (iv) transportation (especially trucking, water, and rail).

Table 7 presents selected cuts of the Bureau of Labor Statistics’ industry-level TFP data. The slowdown for the entire private business economy (line 1) after 2004 is marked. Finance slows sharply after 2004 and shows no further slowdown after 2007, the period of Dodd-Frank and other regulatory restrictions. With fracking, energy industries experienced faster productivity growth after 2007, so recent regulatory restraints on energy do not explain slow productivity growth. Construction also has experienced less negative productivity growth. Of heavily regulated industries, only transportation (2.5 percent of value added) has seen lower TFP growth.

Finance could matter, of course, as an intermediate provider of services. Using the inputoutput tables, we divided industries into finance-intensive (row 8) and non-finance-intensive (row 9) industries, defined by the expenditure share of financial services in industry gross output. Both groups slow sharply after 2004, but the finance-intensive grouping actually improve after 2007, despite increasing finance regulation. During the entire post-2004 period, the slowdown is larger for non-financial-intensive industries. Thus, it does not appear that post-2008 financial restrictions were a major impediment to productivity growth. 
Third, we find little evidence of a broader regulatory effect. Table 8 shows panel regressions of industry productivity growth on current and lagged values of growth in industry regulatory restrictions. All regressions include industry fixed effects; the second column includes year effects. Columns 1 and 2 show that, with one and two lags, growth in regulatory restrictions is statistically insignificant and the explanatory power is tiny. Columns 3 and 4, which average lagged values, also show small and statistically insignificant effects. These negative findings are consistent with those of Nathan Goldschlag and Alexander Tabarrok (2014), who find that changes in U.S. federal regulations have little or no effect on industry entrepreneurial activity or dynamism.

The lags might be long and uncertain; the data could be too noisy; or the regulations that matter could mainly be at the state and local levels (for example, land use restrictions and occupational licensing). However, at a first cut, we find no evidence that federal regulation is a firstorder issue.

3. A PAUSE IN THE INFORMATION TECHNOLOGY REVOLUTION The hypothesis that information technology (IT) was the culprit is natural. A large body of literature links the mid-1990s speedup in productivity growth to the exceptional contribution of computers, communications equipment, software, and the Internet. IT has had a broad-based and pervasive effect on the economy through its role as a general purpose technology (Bresnahan and Trajtenberg 1995; David and Wright 2003; Basu and others 2004). Businesses throughout the economy became more efficient by reorganizing to take advantage of an improved ability to manage information. However, by the early 2000s, industries like retailing had already been substantially reorganized, so the gains from further innovation might have become more incremental (Gordon 2016; Fernald 2015).

Table 7 suggests some evidence consistent with this hypothesis. IT-producing industries (line 6) grew much more slowly after 2000 and even more slowly after 2007. Industries that use technology intensively showed a larger slowdown after 2007 relative to the 2000-04 period. But it is fair to say that this slowdown was broad-based. All industries use IT, and increasingly so. If that is the story, one might see another such period in the future, perhaps reflecting artificial intelligence, cloud computing, the Internet of Things, and the radical increase in mobility from smartphones. But we have not yet seen such gains in the data. 
This story rings true in a number of ways. First, it is consistent with the large body of literature on the role of IT in the productivity acceleration of the late 1990s. Second, it is consistent with the view in the general-purpose-technology literature that the gains are, essentially, a series of drawn-out level effects. The gains might ebb and flow (Syverson 2013), and it is hard ex ante to know when the transformative gains will cease.

\section{FALLOUT FROM THE RECESSION AND FINANCIAL CRISIS Our use of cyclically} adjusted productivity growth corrects for normal cyclical movements in productivity and allows us to focus on the magnitude and timing of the more persistent, secular slowdown that has been the focus of this section so far. But a large body of literature argues that deep recessions, and especially financial crises, might reduce the level or growth rate of TFP (for an early review, see Fatás 2000; for more recent discussions, see David Reifschneider, William Wascher, and David Wilcox, 2015, as well as Adler and others 2017). For example, a crisis might reduce investment in innovation or raise capital misallocation. If these channels are important, then a high-pressure economy might help reverse these effects and lead to faster growth in innovation (Yellen 2016)

Nevertheless, theory suggests that effects could go in either direction. For example, reallocation effects could raise higher productivity in a credit crisis (Petrosky-Nadeau 2013), as could cleansing effects (Caballero and Hammour 1994). Nicholas Bloom (2014) points out that higher uncertainty can stimulate longer-run innovation.

Overall, there is limited empirical evidence for the United States that historical downturns in the business cycle, financially related or otherwise, permanently cut the level or growth rate of productivity. An obvious counterexample is the depressed 1930s, which were an extraordinarily innovative period, by all accounts (Field 2003; Alexopoulos and Cohen 2011; Gordon 2016). More broadly, Yu-Fan Huang, Sui Luo, and Richard Starts (2016) find that the level of TFP bounces back quickly from recessions, including after 2009. This evidence is consistent with the view that lower frequency swings in productivity growth rates are largely exogenous to the business cycle.

The biggest challenge for explaining the recent U.S. data is the timing: Productivity growth slowed before the recession. Diego Anzoategui and others (2016) suggest that there might have been a prerecession shock to exogenous growth followed by the large shock from the recession. Yet, as 
noted above, measured U.S. investments in research and development and other intellectual property slowed markedly after 2000, with a much smaller effect during the recent recession.

In sum, it is difficult to measure counterfactual productivity growth absent the recession, or absent the regulatory tightening. But we find that the weight of the evidence suggests that the slow pace of growth since the mid-2000s is real, and has contributed substantially to the disappointing recovery, and — with roots in the temporary, IT-spurred productivity boost of the 1990s-may even continue.

\section{Changes in the Labor Market}

The trends in labor force participation for men and women were very different than in earlier years, with women rising and men falling. As shown in figure 11, however, both have moved together since 2006 and both have fallen sharply since 2008. This decline has exerted a large negative force on output growth. Table 3 above shows that the contribution of participation to output, after cyclical adjustment, was -0.69 percentage point per year (column e), compared with an increase of 0.15 point per year averaged over the three previous recoveries (column d), for a shortfall of 0.85 point per year (column f). Cumulated over the recovery period through 2016, the shortfall was 6.11 percentage points (column i), almost as large as for TFP.

Before the crisis, recessions depressed labor force participation, though there were forces on both sides. Higher unemployment discouraged participation because it took longer to find a job. On the flip side, declines in income and wealth raised participation by inducing more people to seek and take jobs. The cyclical coefficient given in table 2 is small $(-0.16)$ over a sample period that includes the rise in unemployment and fall in participation during and after the recession. This generalized Okun's coefficient increases in specifications allowing for slower adjustment; with three years of lags, it is -0.37 . Regardless of the lag specification, however, by 2016 the normal cyclical component of the participation rate was essentially zero.

Our estimate of the cyclical sensitivity of participation is larger if we end our sample before the crisis. Although the period of rising unemployment saw declines in participation, the recovery involved falling unemployment and falling participation, and that experience outweighed the contribution from the contraction. Key to our conclusions about participation is the fact that, until 
recently, participation continued to fall as unemployment declined from its peak of 10 percent to normal levels below 5 percent. This episode would be hard to explain if cyclical developments dominated participation toward the end of the recovery.

Many researchers ascribe part of the decline in participation to demography, specifically to the rising fraction of the population age 55 years and above. Older individuals are more likely to retire. But adjusting for age composition alone, or just age and sex, misses countervailing demographic forces that reduce the propensity to retire. In particular, the people who moved into the 55+ age group during the recovery are better educated than their predecessors, and better-educated workers tend to retire later than less-educated workers. Estimates of pure aging declines in participation, which use historical rates for older workers, could overstate the contribution of aging during the recent recovery. Instead, we calculate indexes that adjust for five demographic dimensions of heterogeneity in the working-age population.

The measured overall labor force participation rate can be written as $L=\sum_{i} s_{i} L_{i}$, where is the population share and is the participation rate of demographic group . The change in the overall participation rate thus satisfies

$$
\Delta L=\sum_{i} s_{i} \Delta L_{i}+\sum_{i} L_{i} \Delta s_{i}
$$

to a high degree of accuracy, especially if $s_{i}$ in the first term and $L_{i}$ in the second are measured as equally weighted values from the earlier and current periods. The cumulation of the first term is the component of the level of participation attributable to changes in participation within demographic groups and the cumulation of the second term is the component attributable to composition changes in the population. We call these the rate and share effects. Indexes calculated this way are named after François Divisia, and the refinement of measuring shares as equally weighted averages is named after Leo Törnqvist. The variation in the rates during the period is large enough to make any share index with fixed rates misleading. Counterfactual calculations based on holding rates at, say, the 2006 or 2016 levels are effectively fixed-rate indexes.

We implement the decomposition in equation (10) with annual data from the Current Population Survey for about 6,100 detailed cells defined by 67 age categories; two sexes; four 
education groups; four race groups; and three marital status groups. A few hundred cells in each year are empty. Figure 12 shows the overall labor force participation rate and our rate index. The difference between the two indexes is effectively our index of the share effect, that is, the effect of changing demographics. During the recovery, from 2010 through 2016, the reported participation rate across the population age 16 and older fell by 1.8 percentage points. Of this, 1.2 points came from the rate effect - the result of lower participation, on average, within demographic groups — and 0.6 point came from compositional change. In other words, forces other than demography accounted for about two-thirds of the overall decline during the recovery, and for about half the decline since the cyclical peak in the fourth quarter of 2007.

The key question is: What explains the large nondemographic decline in the participation rate? Some specifications suggest that the cyclical component of the participation rate is larger than in our specification here (see Erceg and Levin 2014; or see our longer-lag results reported in the online appendix). Even with a large cyclical coefficient, however, by the middle of 2016, the unemployment rate had returned to a normal or near-normal range, leaving only a very small normal cyclical component by mid-2016.

If the nondemographic participation gap as of 2016 is not part of a normal cyclical pattern, could it reflect unusual features of this recession and recovery? We think not. The 5.5 percentage point increase in the unemployment rate from its 2006 trough to its 2009 peak was comparable to the 5 percentage point increase from its 1979 trough to its 1982 peak spanning the twin recessions of the early 1980s. As shown in figure 1, the unemployment rate initially fell more sharply in the first 18 months following its peak in 1982 than following its 2009 peak; but the rate then plateaued. During the five years following its 2009 peak, the unemployment rate fell by 0.9 percent per year, nearly as fast as the 1.0 percent per year decline following the 1982 peak. Because the cyclical movements of the early 1980s are part of the data used to estimate the Okun's law coefficients, explanations that appeal to hysteresis must therefore argue that the correlations from previous cycles do not translate to the current cycle. It is not possible to estimate these coefficients precisely using only the current cycle; but, if anything, the unemployment coefficients are smaller when the current cycle is included in the data set. Finally, a related concern could be that the Okun coefficients are different for 
increasing than decreasing rates of unemployment, so our cyclical estimate is misspecified; but we find no evidence of such an asymmetry.

Aaronson and others (2014) report a variety of results for labor force participation. They find that their forecasts of participation published in 2006 were remarkably accurate as of 2014, suggesting that the entirely unforeseen recession and recovery that began at the end of 2007 had little net effect on participation. Their overall conclusion is that the sources of the decline in participation are partly demographic and partly a change that is not much related to conditions in the labor market. Though they do not specifically discuss the post-2009 expansion, it appears that their results (and others' they cite) confirm our conclusion that the dramatic improvement in the labor market during the recovery had little net effect on participation.

Our conclusion is that the roots of the nondemographic participation gap as of 2016 lie somewhere other than in the recession. Research has so far been inconclusive about the sources.

Figure 13 shows labor force participation rates for people age 25 through 54 by family income. Between 2004 and 2013, participation rose among members of the poorer half of families, and fell substantially in the upper half, the third and fourth quartiles. Essentially, all the decline in participation occurred in families with higher incomes. This finding contradicts the hypothesis that the decline in participation reflects the marginalization of poorer families in the labor market.

Table 9 investigates how people spent the time freed up by reduced work hours. It compares time allocations in 2015 with those in 2007. Market work, including time spent on job searches, fell by 1.6 hours a week for men and by 1.4 hours for women. The two categories with increases were personal care and leisure, which include a large amount of TV watching and other video-based entertainment, especially for men. The drop in hours devoted to other activities included a decline in housework for women. Basically, time use shifted toward enjoyment and away from work and investment activities. There was no substitution from market work to either nonmarket work or investment in human and household capital.

The surprising, large, and persistent decline in labor force participation is a phenomenon that deserves and will receive intensive study. Although there is room for disagreement about the extent to which the early-recovery decline in labor force participation reflected a weak labor market, that 
cyclical component was gone by mid-2016. Similarly, although demographic shifts are and will continue to be an important part of the decline in the participation rate, demographics provide only a partial explanation. The complete explanation will also consider changes in family structure, real wages, taxes, benefits, and the value of time spent outside the labor market.

\section{Other Explanations for Slow Output Growth}

So far, our discussion has highlighted the noncyclical role of slow TFP growth and declining participation in explaining slow output growth. Our forecasting model, however, provides some evidence on the large number of other explanations that have been proposed.

Our analysis takes demand into account through the use of unemployment as a cyclical indicator and through the use of a factor model with a multivariate statistical characterization of the cycle. If unemployment rates below 5 percent imply an economy in a cyclically normal condition, then this rules out explanations based on permanent or highly persistent weak demand. Moreover, explanations based on temporary demand deficiency need to be reconciled to the fact that the recovery of the unemployment rate was not abnormally slow-indeed, was faster than expected (figure 2). Sponsors of explanations based on weak demand need to couple their explanations with a parallel explanation of the behavior of labor-market indicators.

\section{VI.A Empirical Evidence from the Forecasting Exercise}

Figure 6, complemented by the full set of factor model forecasts shown in the online appendix, shows three periods in the history of the recovery. From mid-2009 through 2010, the economy grew vigorously, with output, consumption, private fixed investment, and employment all growing at or above the forecasted path. From 2011 through 2013, employment growth, though strong, was below its predicted path, and the associated predicted strong growth in output failed to materialize. This large growth gap reflected the lack of sustained output growth in the 3 to 4 percent range that was typical of earlier recoveries. After an initial surge, the growth of productivity was well below its predicted path. In the third period, since 2014, growth in many aggregates, including output and especially employment, has been stronger than the forecasted path, and-notably—-the slow productivity growth over this period is consistent with the cyclical prediction. This picture is one of a 
recovery delayed; the slow-growth puzzle is largely the absence of strong growth in productivity and output in 2011 through 2013.

The demand decomposition given in table 5 indicates that most of the demand components tracked their forecasted paths, on average. Although exports were unexpectedly weak, so were imports; after share-weighting, their contributions to the average shortfall in output growth were negligible, at 0.03 and -0.01 percentage point per year, respectively. Table 5 indicates that the average forecast error for GDP of 0.57 percentage point is largely attributable to three sources: consumption of services (0.18 percentage point), federal government expenditures (0.15), and state and local government expenditures (0.10).

For federal government purchases, the main shortfall occurred in 2013 and 2014 (figure 6). This period coincides with the fiscal drag associated with the unwinding of American Recovery and Reinvestment Act expenditures and with the sequester. For state and local expenditures, the period of negative contributions was longer, from 2010 through early 2014.

Consumption growth during the recovery was slightly weaker than predicted-a 0.26 percentage point contribution to the output shortfall. Much of this weakness is attributable to two service sectors: housing and utilities (0.07 percentage point) and financial services and insurance (0.07 percentage point). The forecast error in residential investment averaged -0.08 percentage point during the full period, but this masks the housing sector's delayed recovery. Through 2011, the normal, cyclical recovery of housing did not materialize, and housing investment growth did not stabilize on the forecasted path until 2012. The strength of the housing market since 2014 accounts for the negative contribution of residential investment to the output shortfall.

\section{VI.B Discussion}

These forecast errors shed light on some of the explanations for the slow recovery. Explanations in which aggregate demand is held back by unusually retarded growth of consumption —increasing inequality, policy uncertainty, or consumer deleveraging — do not square with the fact that the contribution of consumption growth to the shortfall in output growth was only 0.26 percentage point; rather, consumption growth largely tracked its predicted path during the recovery. Moreover, the largest shortfall in consumption is in services-mainly, housing services, 
and financial services and insurance_-and in the latter case, for only three aberrant quarters in 2011 and 2012. This pattern does not seem to align with any explanation that focuses on shortfalls in aggregate demand that operate through consumption broadly.

Similarly, the evidence does not support theories that operate through slow investment. Nonresidential investment growth was, in fact, unexpectedly strong early in the recovery, and otherwise largely tracked its predicted path, apart from a slow spell in 2013 (figure 6).

The fact that the growth of consumption and investment largely tracked their historical, cyclical patterns suggests that the unusual features of the current recovery that might have restrained aggregate demand are not, in fact, key drivers of the slow recovery. Moreover, one would expect slow aggregate demand to be reflected in sluggish revival of employment and the unemployment rate, but that is evidently not the case because employment growth exceeded the 2009 prediction on average. Growth was strong early and late in the recovery.

Our examination of the expenditure components revealed one part of demand that made a contribution to the slow recovery: weakness in federal, state, and local government purchases. The timing of the forecast errors suggests that the unwinding of the American Recovery and Reinvestment Act spending combined with the sequester provided substantial headwinds to the recovery. In addition, the persistently slow growth of state and local government purchases through 2013, along with the slow growth during this period of state and local government employment, points to an unusually severe fiscal drag imparted by restrained state and local purchases associated with balanced budget requirements and the prolonged effect on real estate tax receipts of the fall in house prices during the recession. These measures do not include transfers, which, unlike direct government purchases, were growing; thus transfers may have somewhat supported consumption. Nevertheless, as shown by the addendum line in table 5, there was a large shortfall in government expenditures plus transfers. This composite category was forecasted to grow by 2.86 percent per year, but in fact it only grew at a 0.66 percent pace.

Finally, we find some room for explanations associated with a poor or missed measurement of real output. Gross domestic income growth averaged 2.34 percent from 2009 to 2016, while GDP grew at 2.06 percent. Table 5 suggests that some of this difference may come from unexpected 
sources. In particular, half the unexpected decline in services consumption in 2013 is attributable (in a national accounting sense) to a decline in one of the most poorly measured sectors of consumption: financial services and insurance. Additional investigation of these measurement issues is warranted.

\section{Concluding Remarks}

Output grew substantially less during the recovery from the 2007-09 recession than would normally have accompanied the observed, relatively rapid decline in the unemployment rate. It grew less than it would have given its normal relation to an index derived from many macroeconomic indicators. And it grew less than professional forecasters predicted, both at the time of the trough and throughout the recovery. An explanation for poor output growth needs to start with two key facts: Productivity grew substantially less than its historical growth rate, both in expansions and in general; and labor force participation shrank an atypical and unexpected amount. Research on both topics is active today. We conclude in this paper that the large movements in both factors were in train before the recession, and cyclical effects contributed at most modestly to them.

Will growth pick up in the future, or slow further? The median respondent in the Survey of Professional Forecasters for the first quarter of 2017 forecasts growth in the next 3 years, and the next 10 years, to exceed its average pace during the recovery so far. Although changes in technology trends are hard to predict, the analysis in our paper does not support such optimism. The disappointing average pace of growth since 2009 included a large cyclical component that has, as of this writing, largely gone away. The remaining slow underlying pace of growth reflected underlying noncyclical trends that predated the recession. To date, those trends have been persistent, and are not a mismeasurement mirage. Although a turnaround in productivity growth could happen again, such a turnaround does not appear to be on the horizon. This observation, combined with labor force participation that is persistently declining for both demographic and nondemographic reasons, suggests subdued steady-state output growth for the foreseeable future. 


\section{Data Appendix}

Growth and expenditure-side decompositions of output

Our main growth-accounting data for the U.S. business sector are described in detail in Fernald (2014). Those data are available quarterly, in growth rates, from 1947:Q2 on at http://www.frbsf.org/economic-research/economists/jfernald/quarterly_productivity.xls. The version used in this paper were prepared on December 30, 2016.

For the overall economy, output is measured by real gross domestic product (GDP) and the geometric average of GDP and real gross domestic income (GDI) (see Nalewaik (2010), GreenawayMcGrevy (2011), and Aruoba et al (2012)). We refer to the average as gross domestic output (GDO). Business sector output is also GDO using Fernald's measure.

Per-person values are formed using the civilian noninstitutional population 16 years of age and older from the Bureau of Labor Statistics (BLS) Current Population Survey (FRED series CNP16OV). Other BLS-CPS variables include employment (CE16OV), labor force (CLF16OV) and the civilian unemployment rate (UNRATE). Quarterly data were constructed by averaging the monthly data for each quarter.

Expenditure variables (Table 5) are from the Bureau of Economic Analysis NIPA accounts.

Industry level TFP, finance intensity, and regulation data,

BLS multifactor productivity (MFP) data and industry capital data were downloaded from http://www.bls.gov/mfp/mprdload.htm (accessed September 6, 2016). Growth-rate data run 19882014. The industry classification system is NAICS. See the online appendix to Fernald (2015) for details on how the data were manipulated and aggregated.

IT intensity is based on factor shares, i.e., payments for IT as a share of income. "IT intensive" is the set of industries with the highest IT shares that constitute 50 percent of the valueadded weight (averaged 1987-2014) for the business sector excluding finance and direct IT production. For finance intensity, we aggregated industries from annual BLS I-O tables (accessed February 23, 2017) from http://www.bls.gov/emp/ep_data_input_output_matrix.htm. The finance share was nominal purchases of intermediate financial services as a share of industry gross output. "Finance intensive" is set of business (excluding finance) industries with the highest finance shares constituting roughly half the value-added weight.

Al-Ubaydli and McLaughlin (2015) produced the regulation data, available at regdata.org. The website summarizes the data as "RegData is a database that quantifies the number of individual restrictions in the Code of Federal Regulations and...determines which industries are targeted by those regulatory restrictions.” They match regulations to BEA industries, which we then matched with BLS industries. Not all industries have reliable measures of regulation, and those industries are omitted. The included industries cover more than 80 percent of private value added and, when aggregated, have a similar TFP pattern to overall private business.

Labor force participation rates

The data underlying the demographic and family income decompositions for labor force participation are from the 2005-2016 monthly CPS microdata, accessed via IPUMS. 


\section{References}

Aaronson, Stephanie, Tomaz Cajner, Bruce Fallick, Felix Galbis-Reig, Christopher Smith, and William Wascher. 2014. "Labor Force Participation: Recent Developments and Future Prospects.” Brookings Papers on Economic Activity, Fall: 197-255.

Aaronson, Stephanie, Bruce Fallick, Andrew Figura, Jonathan Pingle, and William Wascher. 2006. "The Recent Decline in the Labor Force Participation Rate and Its Implications for Potential Labor Supply.” Brookings Papers on Economic Activity, no. 1: 69-134.

Adler, Gustavo, Romain Duval, Davide Furceri, Sinem Kiliç Çelik, Ksenia Koloskova, and Marcos Poplawski-Ribeiro. 2017. "Gone with the Headwinds: Global Productivity.” Staff Discussion Note no. 17/04. Washington: International Monetary Fund.

Aghion, Philippe, Antonin Bergeaud, Timo Boppart, Peter J. Klenow, and Huiyu Li. 2017. "Missing Growth from Creative Destruction.” Working Paper no. 2017-04. Federal Reserve Bank of San Francisco.

Alexander, Lewis, and Janice Eberly. 2016. "Investment Hollowing Out.” Paper prepared for the 17th Annual Jacques Polak Research Conference, International Monetary Fund, Washington, November 3.

Alexopoulos, Michelle, and Jon Cohen. 2011. "Volumes of Evidence: Examining Technical Change in the Last Century through a New Lens.” Canadian Journal of Economics 44, no. 2: 413-50.

Al-Ubaydli, Omar, and Patrick A. McLaughlin. 2015. "RegData: A Numerical Database on IndustrySpecific Regulations for All United States Industries and Federal Regulations, 1997-2012.” Regulation \& Governance 11, no. 1: 109-23.

Anzoategui, Diego, Diego Comin, Mark Gertler, and Joseba Martinez. 2016. “Endogenous Technology Adoption and R\&D as Sources of Business Cycle Persistence.” Working Paper no. 22005. Cambridge, Mass.: National Bureau of Economic Research.

Barro, Robert J. 2016. “The Reasons behind the Obama Non-Recovery.” Wall Street Journal, September 20. http://scholar.harvard.edu/files/barro/files/wsj_published version 092116.pdf

Basu, Susanto, and John Fernald. 2001. "Why Is Productivity Procyclical? Why Do We Care?” In New Developments in Productivity Analysis, edited by Charles R. Hulten, Edwin R. Dean, and Michael J. Harper. University of Chicago Press.

Basu, Susanto, John G. Fernald, Nicholas Oulton, and Sylaja Srinivasan. 2004. "The Case of the Missing Productivity Growth, or Does Information Technology Explain Why Productivity Accelerated in the United States but Not in the United Kingdom?” NBER Macroeconomics Annual 18: 9-82.

Blanchard, Olivier, Guido Lorenzoni, and Jean-Paul L’Huillier. 2017. “Short-Run Effects of Lower Productivity Growth: A Twist on the Secular Stagnation Hypothesis.” Working Paper no. 23160. Cambridge, Mass.: National Bureau of Economic Research.

Bloom, Nicholas. 2014. "Fluctuations in Uncertainty.” Journal of Economic Perspectives 28, no. 2: 153-76.

Bosler, Canyon, Mary C. Daly, John G. Fernald, and Bart Hobijn. 2016. “The Outlook for U.S. Labor-Quality Growth.” Working Paper no. 2016-14. Federal Reserve Bank of San Francisco http://www.frbsf.org/economic-research/publications/working-papers/wp2016-14.pdf 
Bresnahan, Timothy F., and Manuel Trajtenberg. 1995. “General-Purpose Technologies: 'Engines of Growth'?” Journal of Econometrics 65, no. 1: 83-108.

Byrne, David M., John G. Fernald, and Marshall B. Reinsdorf. 2016. "Does the United States Have a Productivity Slowdown or a Measurement Problem?” Brookings Papers on Economic Activity, Spring: 109-57.

Caballero, Ricardo J., and Mohamad L. Hammour. 1994. “The Cleansing Effect of Recessions.” American Economic Review 84, no. 5: 1350-68.

Cette, Gilbert, John Fernald, and Benoît Mojon. 2016. “The Pre-Great Recession Slowdown in Productivity.” European Economic Review 88: 3-20.

CBO (Congressional Budget Office). 2006. “The Budget and Economic Outlook: Fiscal Years 2007 to 2016.” https://www.cbo.gov/publication/41661Washington. https://www.cbo.gov/publication/17601

—. 2012. "What Accounts for the Slow Growth of the Economy after the Recession?" Washington. https://www.cbo.gov/publication/43707

Corrado, Carol, and Kirsten Jäger. 2015. "Wealth and Investment in Mature Societies.” Presentation given at Milestone 3: Midterm Conference, Smart Public INTANgibles (SPINTAN), London, April 23-24. http://www.spintan.net/wp-content/uploads/public/Carol-Corrado-Wealth-andInvestment_carol-corrado.pdf

. 2015. “A Better Measure of Economic Growth: Gross Domestic Output (GDO).”

Washington: White House.

https://obamawhitehouse.archives.gov/sites/default/files/docs/gdo_issue_brief_final.pdf

David, Paul A., and Gavin Wright. 2003. "General Purpose Technologies and Surges in Productivity: Historical Reflections on the Future of the ICT Revolution.” In The Economic Future in Historical Perspective, edited by Paul A. David and Mark Thomas. Oxford University Press.

Daly, Mary C., John G. Fernald, Fernanda Nechio, and Òscar Jordà. 2017. "Shocks and Adjustments.” Manuscript, Federal Reserve Bank of San Francisco.

Decker, Ryan A., John Haltiwanger, Ron S. Jarmin, and Javier Miranda. 2016a. "Declining Business Dynamism: What We Know and the Way Forward.” American Economic Review 106, no. 5: 203-07.

—. 2016b. "Where Has All the Skewness Gone? The Decline in High-Growth (Young) Firms in the U.S.” European Economic Review 86: 4-23.

Erceg, Christopher J., and Andrew T. Levin. 2014. "Labor Force Participation and Monetary Policy in the Wake of the Great Recession.” Journal of Money, Credit and Banking 46, suppl. 2: 349.

Fatás, Antonio. 2000. "Do Business Cycles Cast Long Shadows? Short-Run Persistence and Economic Growth.” Journal of Economic Growth 5, no. 2: 147-62.

—. 2016. “The Agenda for Structural Reform in Europe.” In After the Crisis: Reform, Recovery, and Growth in Europe, edited by Francesco Caselli, Mário Centeno, and José Tavares. Oxford University Press.

Fernald, John G. 2014. “A Quarterly, Utilization-Adjusted Series on Total Factor Productivity.” Working Paper no. 2012-19. Federal Reserve Bank of San Francisco.

. 2015. "Productivity and Potential Output Before, During, and After the Great Recession.” NBER Macroeconomics Annual 29: 1-51. 
Fernald, John G., and J. Christina Wang. 2016. "Why Has the Cyclicality of Productivity Changed? What Does It Mean?” Annual Review of Economics 8: 465-96.

Field, Alexander J. 2003. “The Most Technologically Progressive Decade of the Century.” American Economic Review 93, no. 4: 1399-413.

Goldschlag, Nathan, and Alexander T. Tabarrok. 2014. "Is Regulation to Blame for the Decline in American Entrepreneurship?” Working Paper in Economics no. 15-11. Fairfax, Va.: George Mason University.

Gordon, Robert J. 2014. “A New Method of Estimating Potential Real GDP Growth: Implications for the Labor Market and the Debt/GDP Ratio.” Working Paper no. 20423. Cambridge, Mass.: National Bureau of Economic Research.

— 2016. The Rise and Fall of American Growth: The U.S. Standard of Living since the Civil War. Princeton University Press.

Gutiérrez, Germán, and Thomas Philippon. 2016. “Investment-Less Growth: An Empirical Investigation.” Working Paper no. 22897. Cambridge, Mass.: National Bureau of Economic Research.

Hall, Robert, and Nicolas Petrosky-Nadeau. 2016. "Changes in Labor Participation and Household Income.” Economic Letter no. 2016-02. Federal Reserve Bank of San Francisco.

Huang, Yu-Fan, Sui Luo, and Richard Startz 2016. “Are Recoveries All the Same: GDP and TFP?” Working paper. http://econ.ucsb.edu/ startz/Are\%20Recoveries\%20All\%20the\%20Same.pdf

Jorgenson, Dale. 1963. “Capital Theory and Investment Behavior.” American Economic Review 53, no. 2: 247-59.

Jorgenson, Dale W., and Zvi Griliches. 1967. “The Explanation of Productivity Change.” Review of Economic Studies 34, no. 3: 249-83.

Jorgenson, Dale W., Mun S. Ho, and Kevin J. Stiroh. 2008. “A Retrospective Look at the U.S. Productivity Growth Resurgence.” Journal of Economic Perspectives 22, no. 1: 3-24.

Kahn, James A., and Robert W. Rich 2017. "Productivity Remains in Decade-Long Growth Slump.” https://www.newyorkfed.org/medialibrary/media/research/national_economy/richkahn_prod mod.pdf (accessed June 11, 2017).

Lansing, Kevin J., and Benjamin Pyle. 2015. "Persistent Overoptimism about Economic Growth.” Economic Letter no. 2015-03. Federal Reserve Bank of San Francisco.

Müller, Ulrich K., and Mark W. Watson. 2008. "Testing Models of Low-Frequency Variability.” Econometrica 76, no. 5: 979-1016.

Nalewaik, Jeremy J. 2010. “The Income- and Expenditure-Side Estimates of U.S. Output Growth.” Brookings Papers on Economic Activity, Spring: 71-106.

Nyblom, Jukka. 1989. “Testing for the Constancy of Parameters over Time.” Journal of the American Statistical Association 84, no. 405: 223-30.

Okun, Arthur M. 1962. “Potential GNP: Its Measurement and Significance.” Paper no. 190. New Haven, Conn.: Yale University, Cowles Foundation for Research in Economics. https://www.scribd.com/document/347717593/Potential-GNP-Its-Measurement-andSignificance

Oliner, Stephen D., Daniel E. Sichel, and Kevin J. Stiroh. 2007. "Explaining a Productive Decade.” Brookings Papers on Economic Activity, no. 1: 81-137. 
Petrosky-Nadeau, Nicolas. 2013. “TFP during a Credit Crunch.” Journal of Economic Theory 148, no. 3: 1150-78.

Reifschneider, Dave, William Wascher, and David Wilcox 2015. “Aggregate Supply in the United States: Recent Developments and Implications for the Conduct of Monetary Policy.” IMF Economic Review 63, no. 1: 71-109.

Robinson, Peter M. 1988. “Root-N-Consistent Semiparametric Regression.” Econometrica 56, no. 4: 931-54.

Solow, Robert M. 1957. “Technical Change and the Aggregate Production Function.” Review of Economics and Statistics 39, no. 3: 312-20.

Stock, James H. 1989. “Nonparametric Policy Analysis.” Journal of the American Statistical Association 84, no. 406: 567-75.

— 2016. "Dynamic Factor Models, Factor-Augmented Vector Autoregressions, and Structural Vector Autoregressions in Macroeconomics.” In Handbook of Macroeconomics, Volume 2A, edited by John B. Taylor and Harald Uhlig. Amsterdam: North Holland.

Syverson, Chad. 2013. "Will History Repeat Itself? Comments on 'Is the Information Technology Revolution Over?’” International Productivity Monitor 25: 37-40.

—. 2016. "Challenges to Mismeasurement Explanations for the U.S. Productivity Slowdown.” Working Paper no. 21974. Cambridge, Mass.: National Bureau of Economic Research.

Tobin, James. 1969. “A General Equilibrium Approach to Monetary Theory.” Journal of Money, Credit and Banking 1, no. 1: 15-29.

Yellen, Janet L. 2016. "Macroeconomic Research After the Crisis.” Speech given the 60th Annual Economic Conference, “The Elusive 'Great' Recovery: Causes and Implications for Future Business Cycle Dynamics,” Federal Reserve Bank of Boston, Boston, October 14.

Zhang, Ting, and Wei Biao Wu. 2012. “Inference of Time-Varying Regression Models.” Annals of Statistics 40, no. 3: 1376 
Figure 1: Unemployment and Output

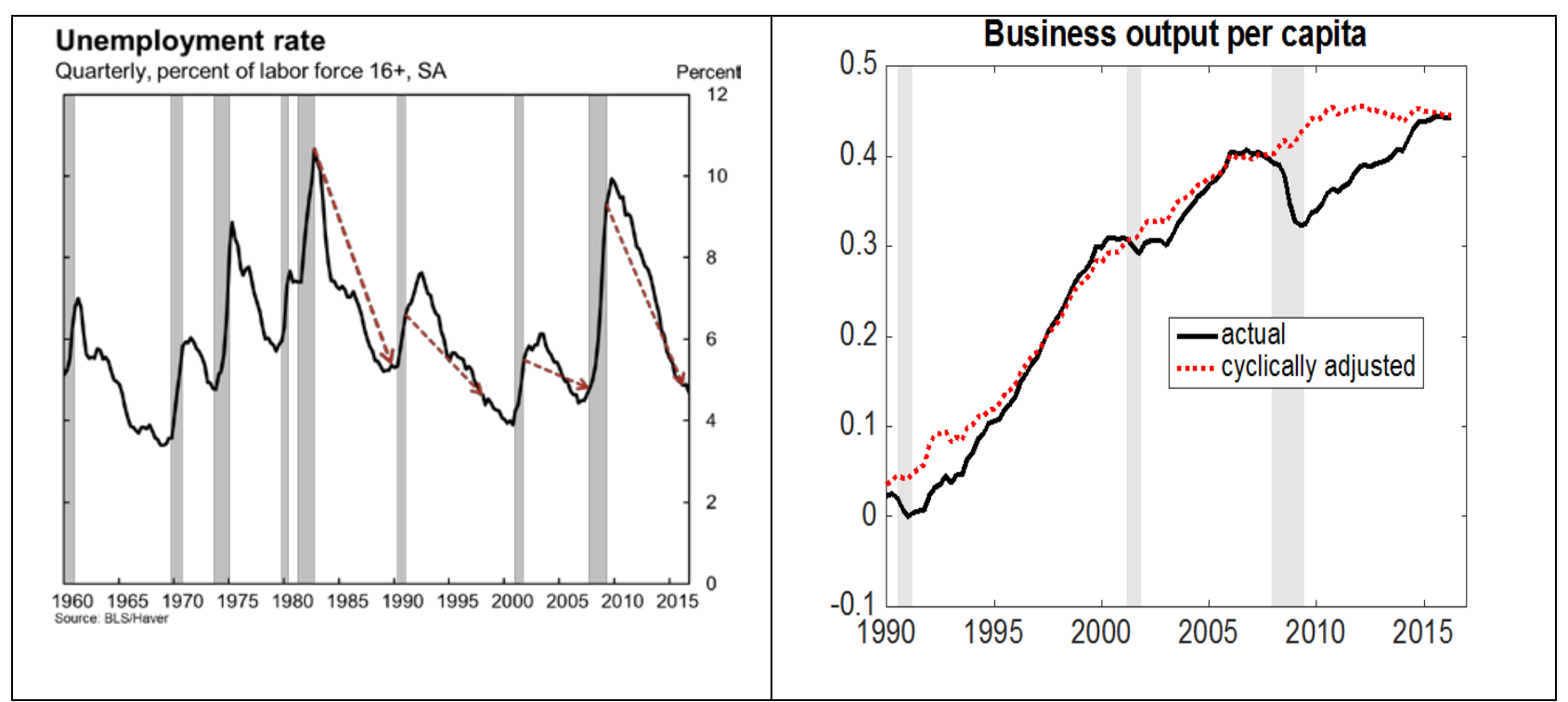

Notes: In the left panel, arrows connect the unemployment rate at the NBER-dated troughs with the rate 28 quarters later (or at the next peak, whichever comes first). In the right panel, the solid black line is the log of business output per person (normalized to 0 in 1991); the dashed red line cyclically adjusts those data using Okun’s Law as described in the text (normalized to equal the solid line in 2007Q3).

Figure 2. SPF Forecasts of GDP and the Unemployment Rate, made in 2010 through 2015

Unemployment: Actual and SPF Projections

Annual

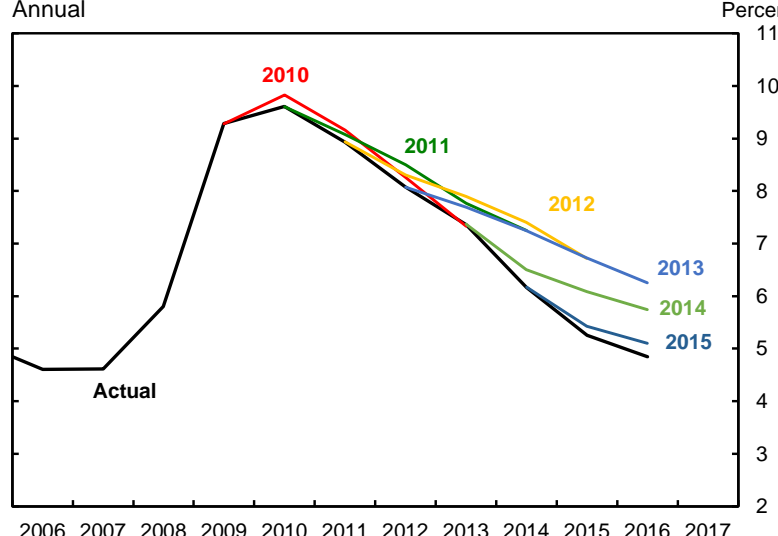

20062007200820092010201

\section{GDP: Actual and SPF projections}

Annual Trillions $2009 \$$

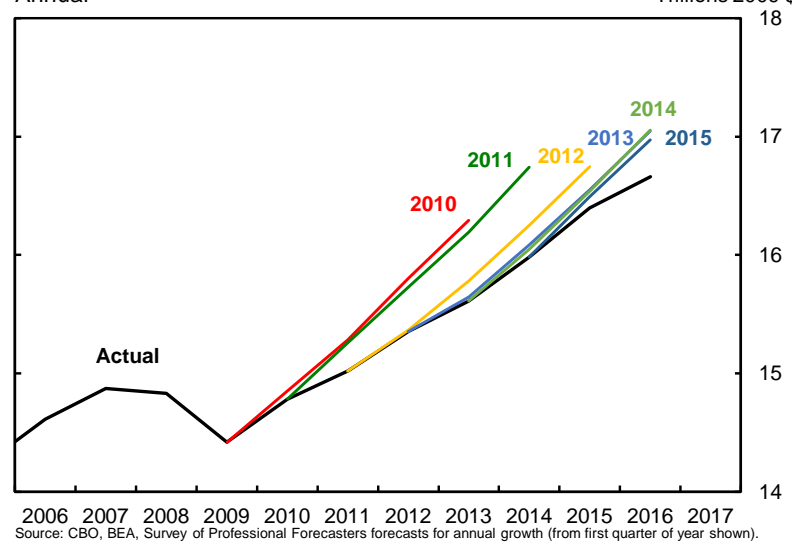

Notes: Median forecasts from the Survey of Professional Forecasters are from the first quarter of year indicated for annual averages of unemployment and GDP growth in that and subsequent years. The GDP figure on the right assumes the previous year's (revised) level is known and then projects using the published forecasts for annual growth rates. For example, the line for 2010 starts at 2009 actual, and uses 2010Q1 forecasts for annual growth in years 2010 on. The GDP figure follows Lansing and Pyle (2015). 
Figure 3: Data and Okun's Law Filtered Data: Output and Labor Productivity

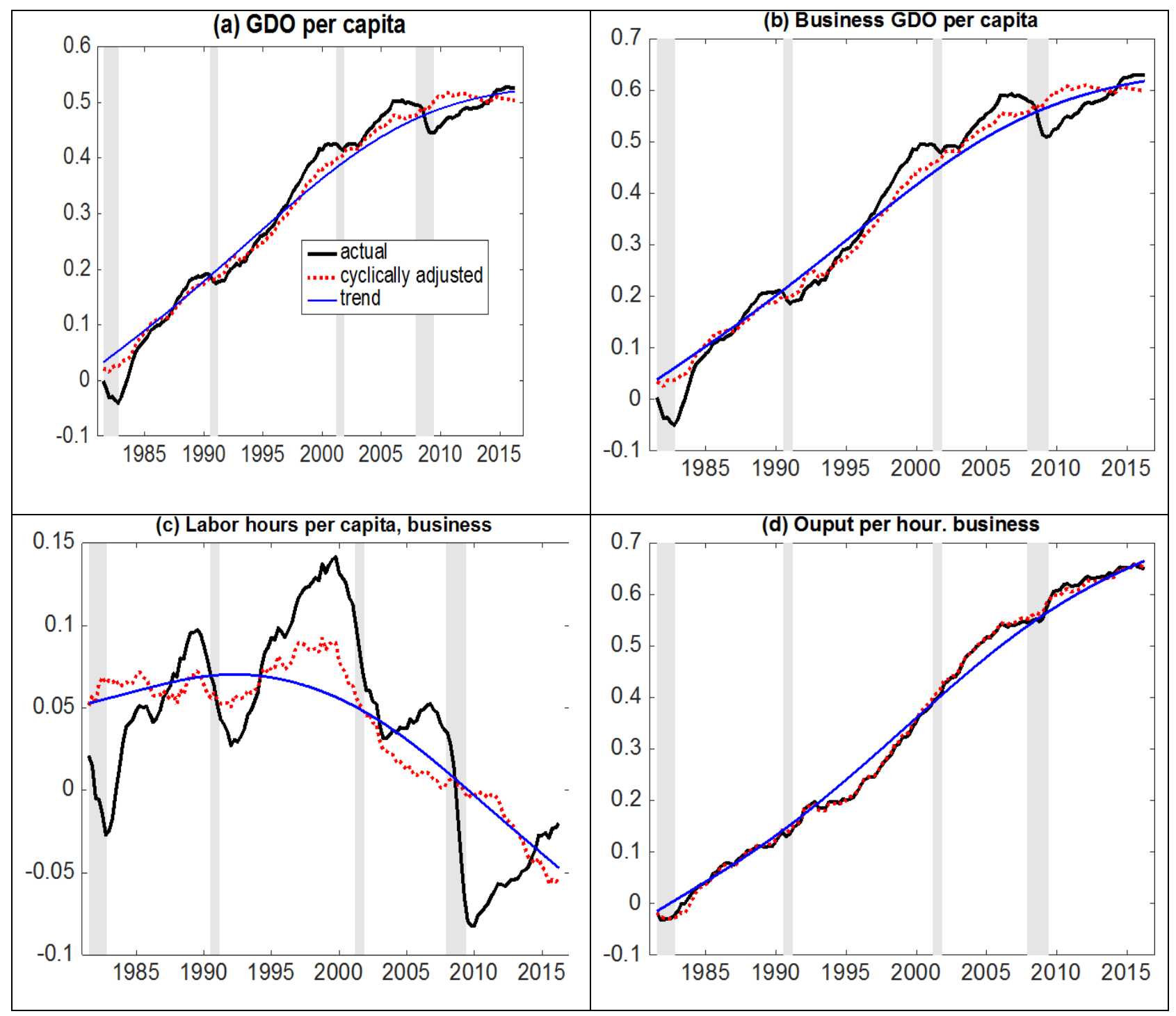

Notes: Plots of cumulated growth rates. Black lines are raw data, red lines are residuals (including constant terms) from Okun's Law regressions. Blue line is biweight filtered trend (bandwidth 60 quarters) fitted to the Okun's Law residuals. Levels are normalized to have the same means over the sample shown. 
Figure 4: Data and Okun's Law Filtered data: Labor Market Variables

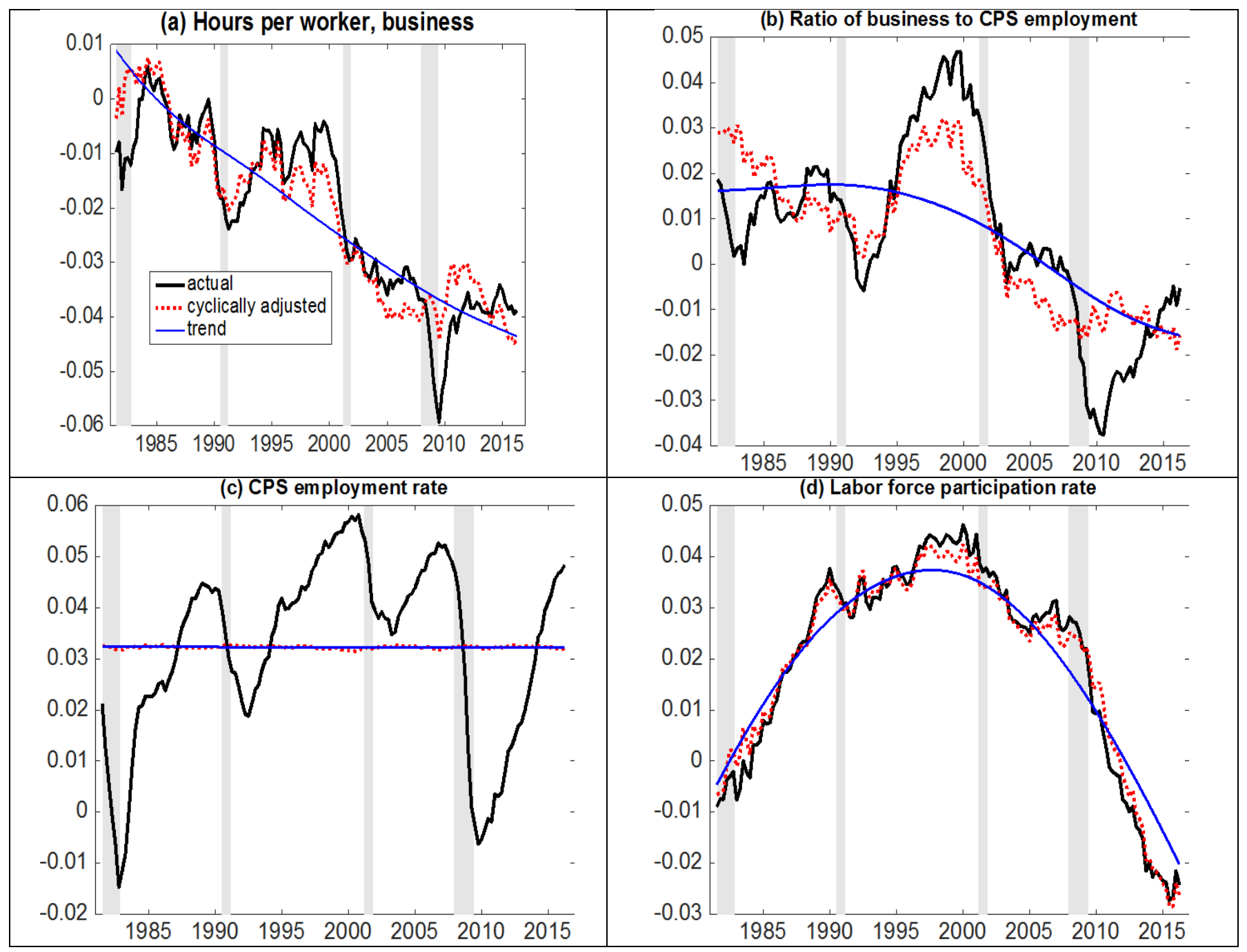

Notes: See Figure 3. 
Figure 5: Data and Okun's Law Filtered Data:

Productivity, Capital Ratios, and Labor quality



Notes: See Figure 3. 
Figure 6. Forecasted and Actual Paths from the Factor Model: Selected Variables

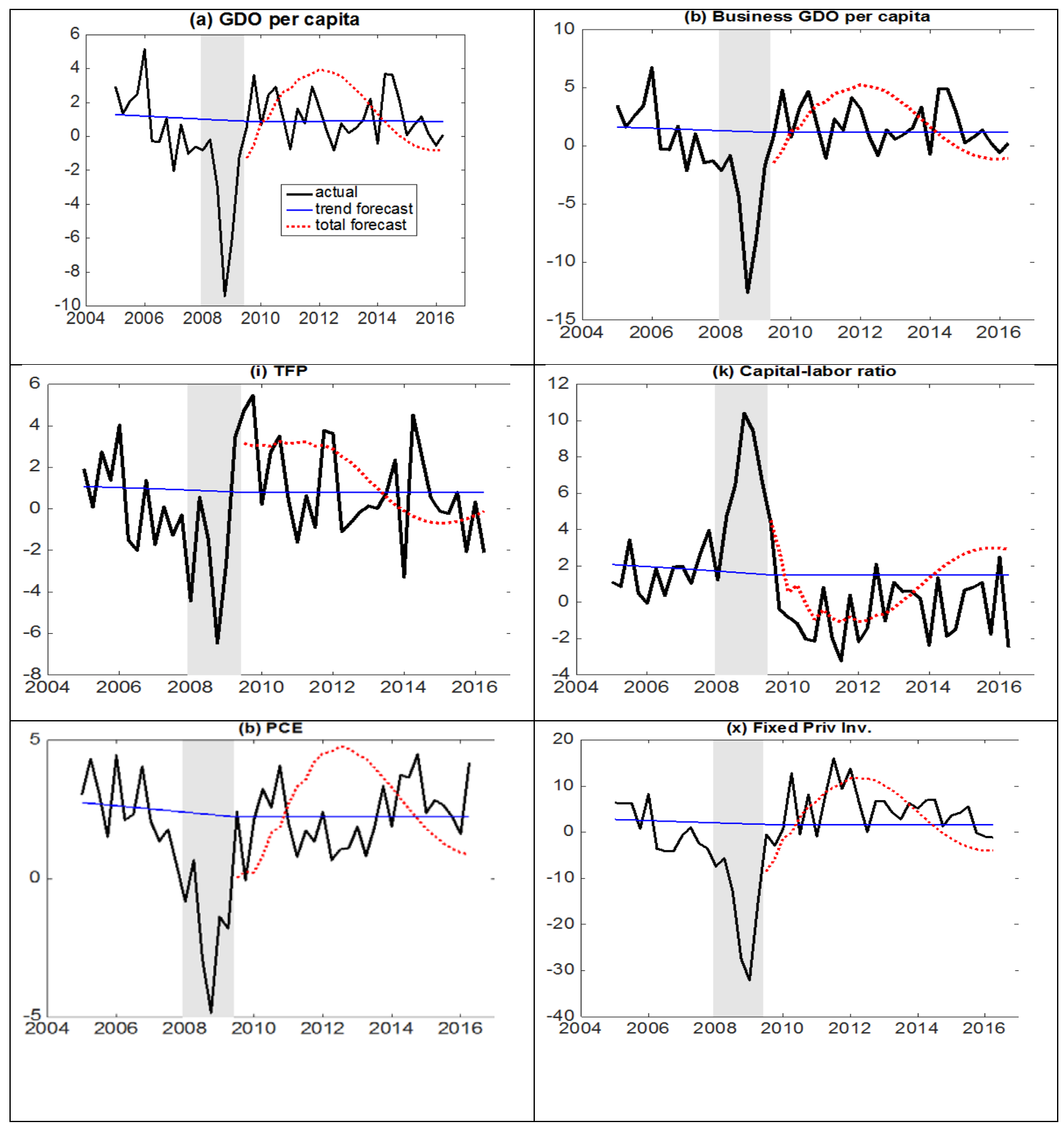


Figure 6, continued

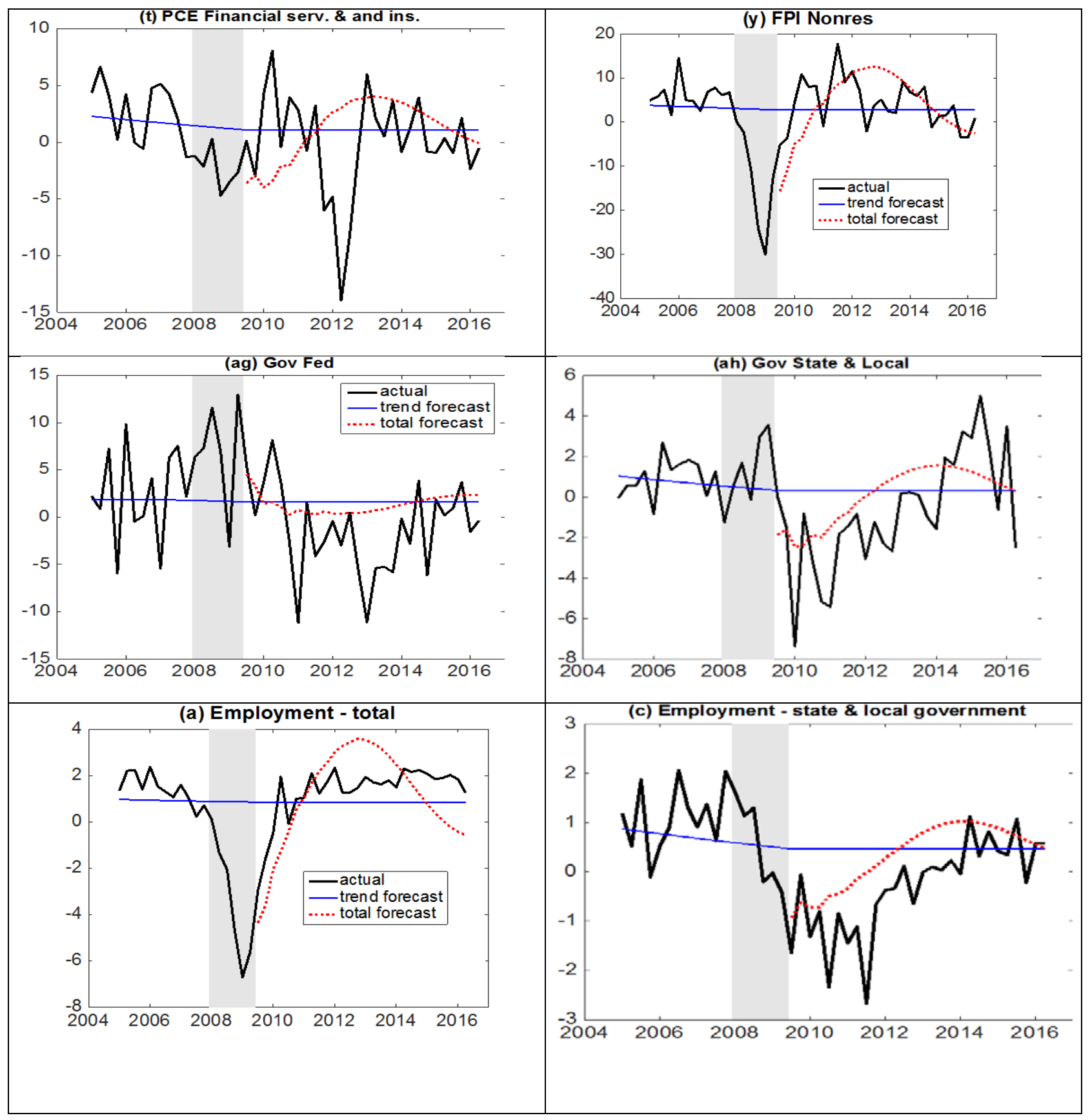

Notes Black line is the actual growth rate of the variable, red line is its forecast based on the six factors, and the blue line is the long-term growth trend. 
Figure 7: Real-Time Estimates of Prospective 10-year Growth in Labor Productivity Output per hour: Forecast and lagged actual

Annual average growth

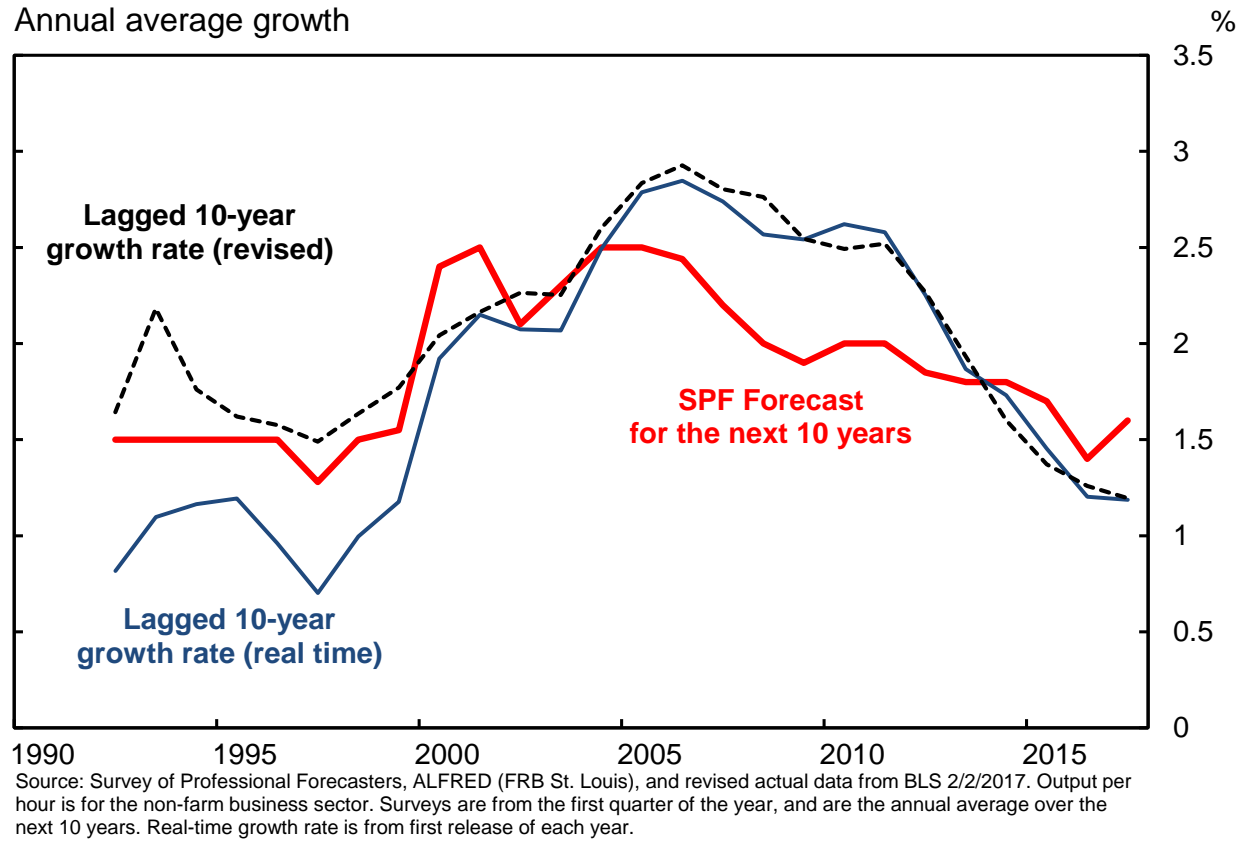

Figure 8: Cyclically-Adjusted TFP Growth and Estimated Low-Frequency Means

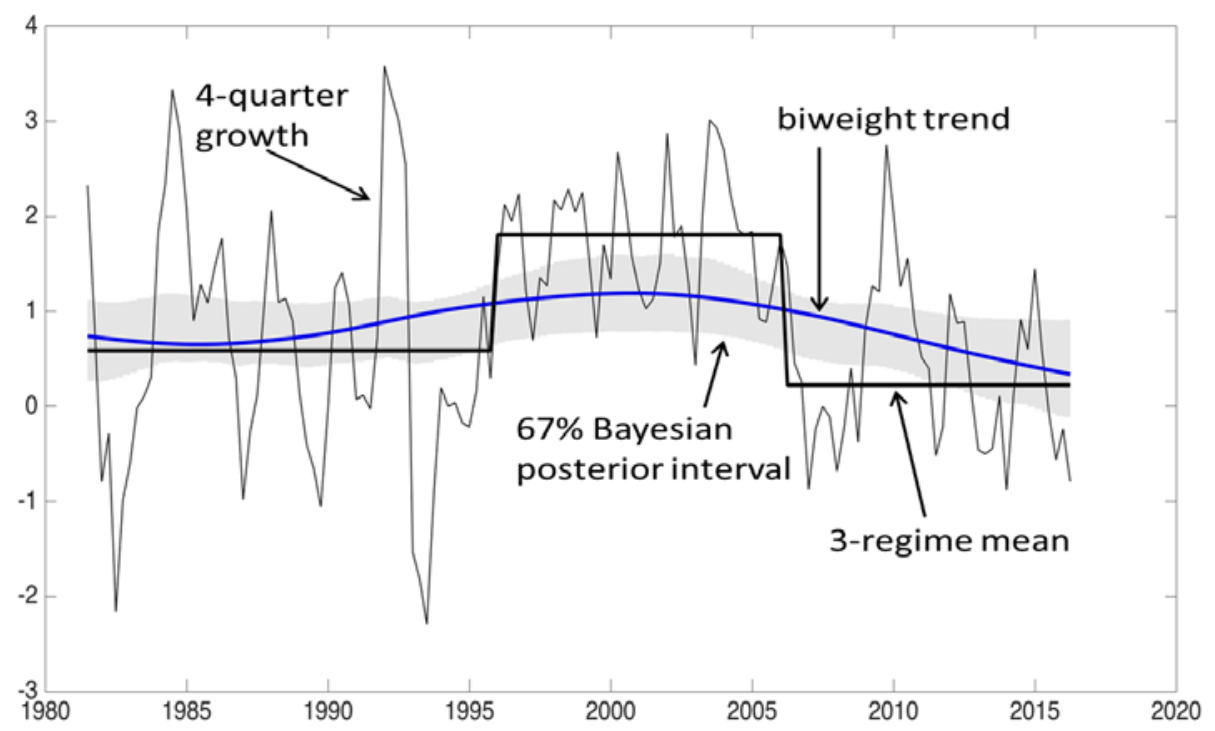

Notes: TFP is cyclically adjusted. The thin black line is its four-quarter growth rate. The blue line is the cyclically-adjusted trend using a biweight filter (60-quarter bandwidth). The shaded area is a $67 \%$ Bayes posterior set. The dark black line are the means estimated within the three regimes estimated by break tests, with break dates in 1995Q4 and 2006Q1 from Table 6. 
Figure 9: Posterior Density of Date of Maximum Trend Growth in TFP, 1981-2016

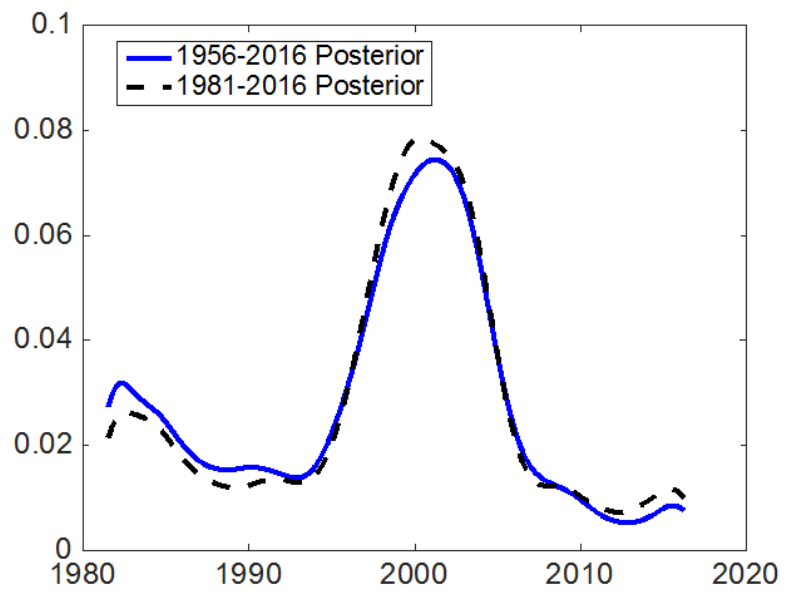

Notes: TFP growth is cyclically adjusted. Computed using Bayes implementation of the random walkplus-noise model for productivity growth, as discussed in the text.

Figure 10. Business Earnings as a Ratio to the Value of Capital



Source: Authors’ calculations.

Figure 11: Labor-Force Participation Rates by Sex, 2006-2016

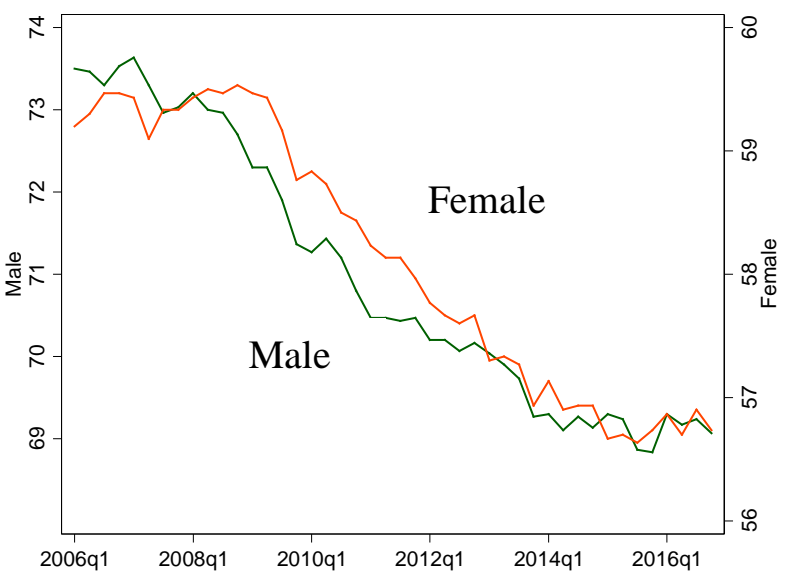

Source: Bureau of Labor Statistics 
Figure 12. Labor-Force Participation Rate, Actual and Adjusted for Changing Demography, Annual 2006-2016

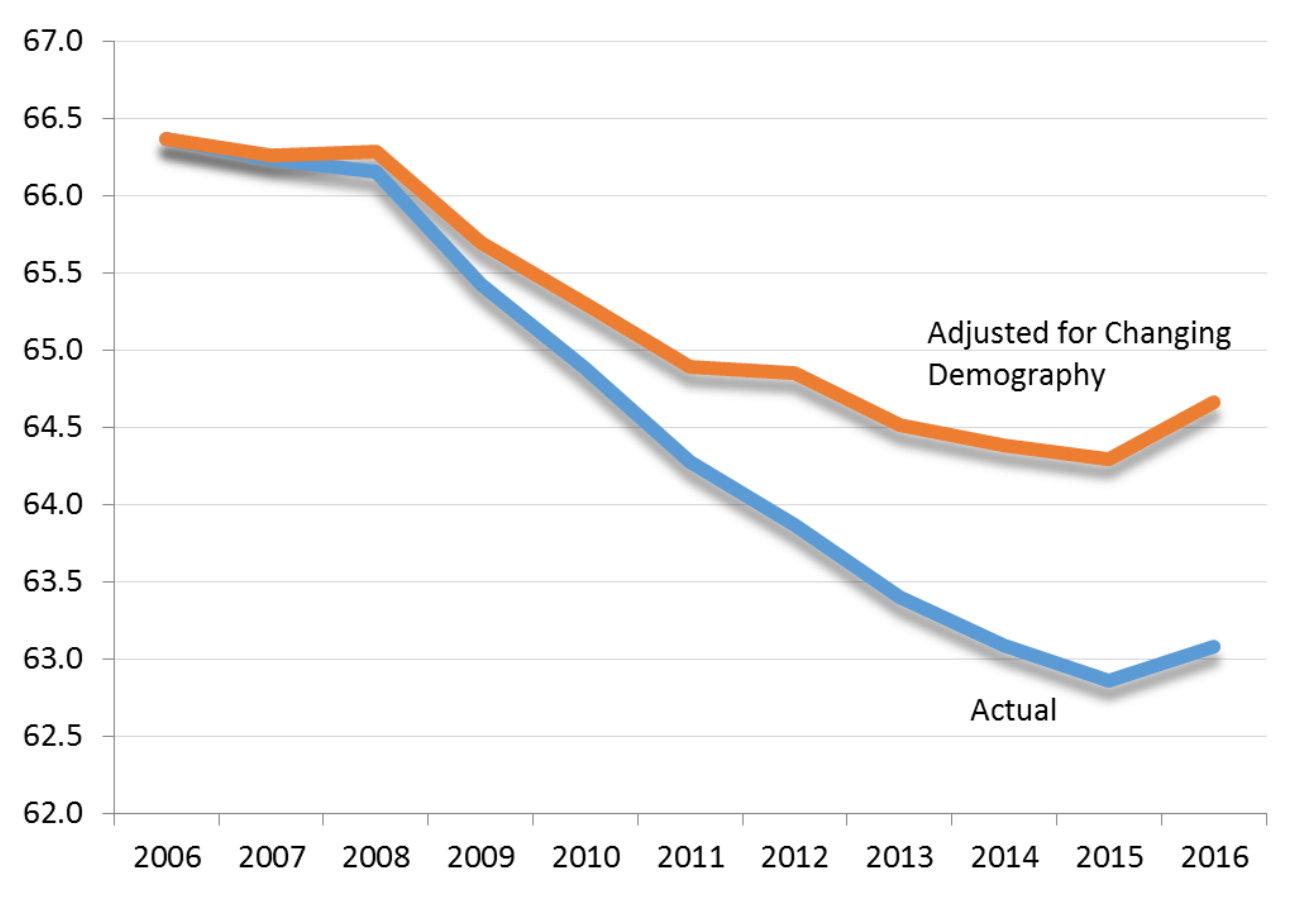

Figure 13. Role of Family Income in Participation Rates

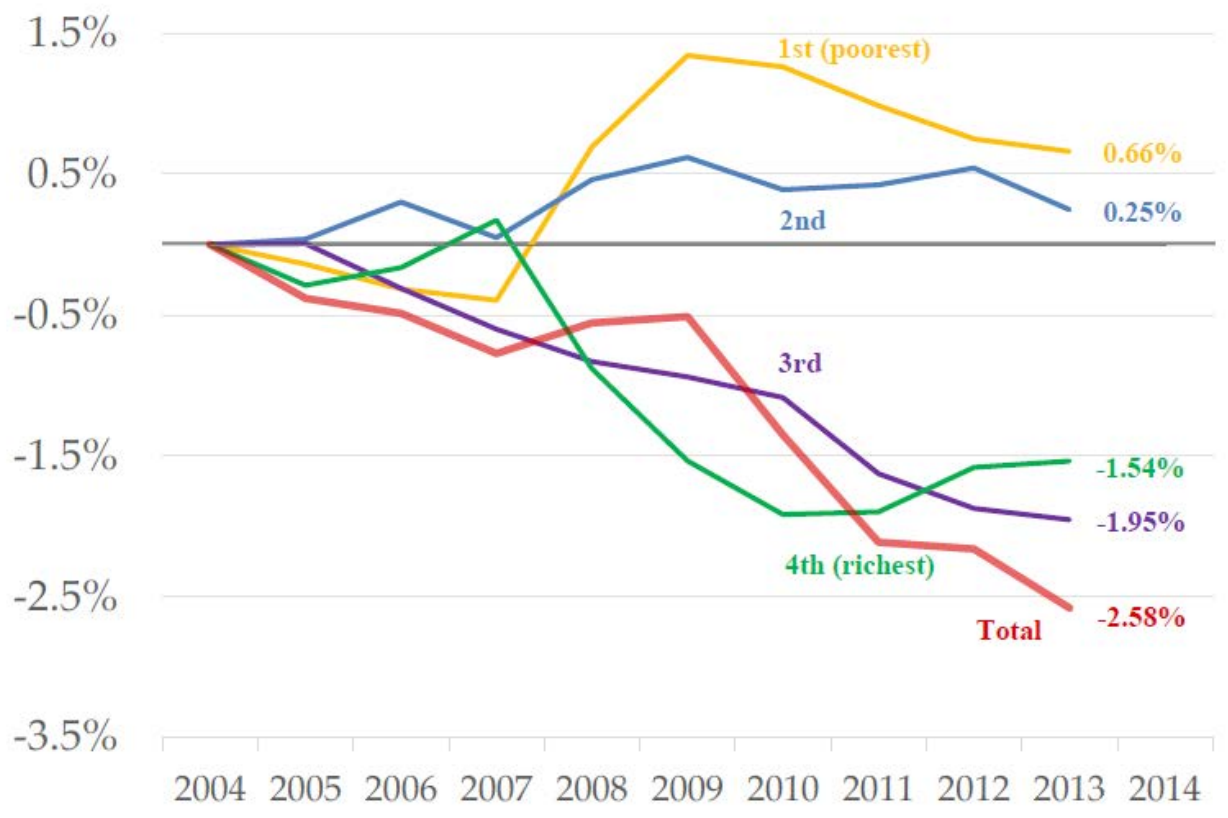

Source: Hall and Petrosky-Nadeau (2016). 
Table 1. Categories of Quarterly Time Series Used to Estimate the Factors

\begin{tabular}{|l|l|c|}
\hline \multicolumn{1}{|c|}{ Category } & Number of series \\
\hline$(1)$ & NIPA & 12 \\
\hline$(2)$ & Industrial Production & 7 \\
\hline$(3)$ & Employment and Unemployment & 30 \\
\hline$(4)$ & Orders, Inventories, and Sales & 8 \\
\hline$(5)$ & Housing Starts and Permits & 6 \\
\hline$(6)$ & Prices & 24 \\
\hline$(7)$ & Productivity and Labor Earnings & 5 \\
\hline$(8)$ & Interest Rates & 9 \\
\hline$(9)$ & Money and Credit & 5 \\
\hline$(10)$ & International & 9 \\
\hline$(11)$ & Asset Prices, Wealth, Household Balance Sheets & 9 \\
\hline$(12)$ & Oil Market Variables & 6 \\
\hline & \multicolumn{2}{|}{} \\
\hline & Total & 123 \\
\hline
\end{tabular}

Notes: For the full list of series and data transformations see the supplemental data appendix. 
Table 2. Cyclicality of Real Output and its Components

\begin{tabular}{|c|c|c|c|c|c|c|}
\hline & & & Standard & viations of & mponents & \\
\hline & & coefficient and std. error & cycle (c) & $\operatorname{trend}(\mu)$ & irregular (z) & $\begin{array}{c}\text { regressing on } \\
\text { factors }\end{array}$ \\
\hline (1) & $\mathrm{DPP}$ & $-1.49(0.18)$ & 1.90 & 0.58 & 1.77 & 0.66 \\
\hline (2) & DO (Average of GDP, GDI) & $-1.53(0.17)$ & 1.92 & 0.57 & 1.61 & 0.72 \\
\hline (3) & Business GDO & $-2.03(0.21)$ & 2.53 & 0.59 & 2.11 & 0.73 \\
\hline$(4)$ & SP per capita & $-1.48(0.17)$ & 1.88 & 0.52 & 1.84 & 0.60 \\
\hline$(5)$ & DO per capita & $-1.52(0.17)$ & 1.89 & 0.51 & 1.63 & 0.67 \\
\hline$(6)$ & Business GDO per capita & $-2.02(0.20)$ & 2.51 & 0.54 & 2.12 & 0.70 \\
\hline & Total factor productivity & $-0.50(0.19)$ & 1.24 & 0.24 & 2.27 & 0.38 \\
\hline & $\alpha^{*}$ Capital/Pop. & $-0.09(0.06)$ & 0.20 & 0.19 & 0.32 & 0.37 \\
\hline & $(1-\alpha) *($ Lab Qual $*$ Hours/Pop. $)$ & $-1.43(0.14)$ & 1.54 & 0.26 & 1.24 & 0.57 \\
\hline & Bus. labor hours per capita & $-2.30(0.19)$ & 2.54 & 0.36 & 1.51 & 0.74 \\
\hline & Hours per worker, business & $-0.35(0.1)$ & 0.55 & 0.04 & 1.05 & 0.25 \\
\hline & Ratio of bus.empl to CPS empl & $-0.71(0.09)$ & 0.73 & 0.08 & 1.20 & 0.24 \\
\hline & CPS employment rate & $-1.08(0.01)$ & 1.36 & 0.00 & 0.10 & 0.89 \\
\hline & Labor-force participation rate & $-0.16(0.10)$ & 0.32 & 0.33 & 0.87 & 0.02 \\
\hline (15) & Bus. output per hour (labor prod.) & $0.28(0.22)$ & 0.77 & 0.37 & 2.23 & 0.24 \\
\hline$(16)$ & $\mathrm{TFP} /(1-\alpha)$ & $-0.75(0.29)$ & 1.88 & 0.35 & 3.41 & 0.39 \\
\hline (17) & Capital-Output ratio $\times \alpha /(1-\alpha)$ & $0.90(0.09)$ & 1.30 & 0.07 & 1.09 & 0.75 \\
\hline (18) & Labor quality & $0.13(0.05)$ & 0.37 & 0.05 & 0.99 & 0.06 \\
\hline
\end{tabular}

Notes: The Okun's law coefficients are $\beta(1) / 4$, so they are measured in quarterly percentage points of growth per percentage point change in the unemployment rate. The standard deviations of the components are for quarterly growth rates reported in percentage points at an annual rate. The $R^{2}$ is from the regression of the variable on the factors used in factor model. 
Table 3: Shortfall of the Post-Crisis Recovery Relative to Earlier Recoveries: Growth Accounting Decomposition Using Okun's Law Cyclical Adjustment

\begin{tabular}{|c|c|c|c|c|c|c|c|c|c|c|}
\hline & & & torical $v$ & & & & Syclically & adjusted & & \\
\hline & & (not c & & sted) & & & & nual short & & \\
\hline & & $\begin{array}{l}\text { Three } \\
\text { previous } \\
\text { recovs. }\end{array}$ & $\begin{array}{c}\text { 2009Q2- } \\
\text { 2016Q2 }\end{array}$ & $\begin{array}{l}\text { Annual } \\
\text { shortfall } \\
\text { (a)-(b) }\end{array}$ & $\begin{array}{c}\text { Three } \\
\text { previous } \\
\text { recovs. }\end{array}$ & $\begin{array}{c}\text { 2009Q2- } \\
\text { 2016Q2 }\end{array}$ & \begin{tabular}{|c|} 
Cyclically \\
adjusted \\
shortfall \\
(d) - (e) \\
\end{tabular} & $\begin{array}{c}\text { Shortfall } \\
\text { in smooth } \\
\text { trend }\end{array}$ & $\begin{array}{c}\text { Residual } \\
\text { shortfall } \\
(f)-(g)\end{array}$ & $\begin{array}{l}\text { Cumul. } \\
\text { shortfall }\end{array}$ \\
\hline & & (a) & (b) & (c) & (d) & (e) & $(\mathrm{f})$ & (g) & (h) & (i) \\
\hline$(1)$ & GDP & 3.60 & 2.06 & 1.54 & 2.95 & 0.96 & 1.99 & 1.26 & 0.73 & 14.94 \\
\hline$(2)$ & GDO (Average of GDP, GDI) & 3.57 & 2.20 & 1.37 & 2.92 & 1.11 & 1.81 & 1.24 & 0.57 & 13.54 \\
\hline (3) & Business GDO & 4.04 & 2.76 & 1.29 & 3.18 & 1.29 & 1.89 & 1.31 & 0.58 & 14.14 \\
\hline (4) & GDP per capita & 2.48 & 1.02 & 1.45 & 1.84 & -0.07 & 1.91 & 1.13 & 0.78 & 14.30 \\
\hline$(5)$ & GDO per capita & 2.45 & 1.16 & 1.29 & 1.80 & 0.07 & 1.73 & 1.11 & 0.62 & 12.90 \\
\hline (6) & Business GDO per capita & 2.92 & 1.72 & 1.21 & 2.07 & 0.26 & 1.81 & 1.18 & 0.63 & 13.49 \\
\hline & Total factor productivity & 1.30 & 0.89 & 0.42 & 0.99 & 0.28 & 0.71 & 0.36 & 0.35 & 5.12 \\
\hline & $\alpha^{*}$ Capital/Pop. & 0.79 & 0.24 & 0.55 & 0.77 & 0.24 & 0.53 & 0.40 & 0.13 & 3.78 \\
\hline & $(1-\alpha) *($ Lab Qual * Hours/Pop.) & 0.83 & 0.59 & 0.24 & 0.30 & -0.27 & 0.57 & 0.41 & 0.15 & 4.04 \\
\hline & Bus. labor hours per capita & 0.81 & 0.63 & 0.18 & -0.06 & -0.76 & 0.70 & 0.55 & 0.14 & 5.00 \\
\hline & Hours per worker, business & 0.07 & 0.24 & -0.17 & -0.10 & -0.07 & -0.03 & -0.06 & 0.03 & -0.24 \\
\hline & Ratio of bus.empl to CPS empl & 0.12 & 0.37 & -0.25 & -0.11 & 0.01 & -0.12 & 0.06 & -0.18 & -0.83 \\
\hline & CPS employment rate & 0.43 & 0.68 & -0.25 & 0.00 & 0.00 & 0.00 & 0.00 & 0.00 & 0.02 \\
\hline & Labor-force participation rate & 0.19 & -0.66 & 0.85 & 0.15 & -0.69 & 0.85 & 0.56 & 0.29 & 6.11 \\
\hline & Bus. output per hour (labor prod.) & 2.11 & 1.09 & 1.03 & 2.12 & 1.01 & 1.11 & 0.62 & 0.49 & 8.09 \\
\hline (16) & $\operatorname{TFP} /(1-\alpha)$ & 1.95 & 1.44 & 0.51 & 1.48 & 0.51 & 0.96 & 0.48 & 0.48 & 6.98 \\
\hline (17) & Capital-Output ratio $\times \alpha /(1-\alpha)$ & -0.26 & -0.69 & 0.42 & 0.16 & 0.07 & 0.08 & 0.11 & -0.02 & 0.59 \\
\hline (18) & Labor quality & 0.43 & 0.33 & 0.09 & 0.49 & 0.43 & 0.06 & 0.03 & 0.03 & 0.44 \\
\hline
\end{tabular}

Notes: Entries are average annual percent changes or percentage point differences. Indented rows sum to next level of aggregation. Post-crisis recovery period is 2009Q2 through 2016Q2 (28 quarters). The three previous recoveries are the averages during the first 28 quarters from the troughs of 1982 and 1991, and the 24 quarters of the expansion after the 2001 trough. Cyclically-adjusted entries in columns (d) and (e) are residuals from Okun's Law regressions. 
Table 4. Shortfall of the Post-Crisis Recovery Relative to 2009IV Forecasts: Growth Accounting Decomposition Using Forecast-Based Cyclical Adjustment

\begin{tabular}{|c|c|c|c|c|c|}
\hline \multirow{2}{*}{\multicolumn{2}{|c|}{ (1) GDP }} & \multirow{2}{*}{$\frac{\text { Forecast }}{2.63}$} & \multirow{2}{*}{$\frac{\text { Actual }}{2.06}$} & \multicolumn{2}{|c|}{ Shortfall (std. error) } \\
\hline & & & & 0.57 & $(0.07)$ \\
\hline (2) & GDO (Average of GDP, GDI) & 2.63 & 2.20 & 0.43 & $(0.07)$ \\
\hline (3) & 3usiness GDO & 3.11 & 2.76 & 0.35 & $(0.08)$ \\
\hline (4) & GDP per capita & 1.51 & 1.02 & 0.48 & $(0.09)$ \\
\hline (5) & GDO per capita & 1.51 & 1.16 & 0.35 & $(0.07)$ \\
\hline (6) & Business GDO per capita & 1.99 & 1.72 & 0.27 & $(0.09)$ \\
\hline & Total factor productivity & 1.40 & 0.89 & 0.52 & $(0.09)$ \\
\hline (8) & $\alpha^{*}$ Capital/Pop. & 0.43 & 0.24 & 0.19 & $(0.01)$ \\
\hline & $(1-\alpha)^{*}($ Lab Qual $*$ Hours/Pop.) & 0.15 & 0.59 & -0.44 & $(0.05)$ \\
\hline (10) & Bus. labor hours per capita & -0.08 & 0.63 & -0.72 & $(0.06)$ \\
\hline (11) & Hours per worker, business & 0.08 & 0.24 & -0.16 & $(0.03)$ \\
\hline (12) & Ratio of bus.empl to CPS empl & -0.16 & 0.37 & -0.53 & $(0.06)$ \\
\hline (13) & CPS employment rate & 0.26 & 0.68 & -0.42 & $(0.02)$ \\
\hline (14) & Labor-force participation rate & -0.27 & -0.66 & 0.40 & $(0.03)$ \\
\hline (15) & Bus. output per hour (labor prod.) & 2.07 & 1.09 & 0.98 & $(0.08)$ \\
\hline (16) & $\mathrm{TFP} /(1-\alpha)$ & 2.15 & 1.44 & 0.72 & $(0.12)$ \\
\hline (17) & Capital-Output ratio $\times \alpha /(1-\alpha)$ & -0.43 & -0.69 & 0.26 & $(0.03)$ \\
\hline$(18)$ & Labor quality & 0.34 & 0.33 & 0.01 & $(0.04)$ \\
\hline
\end{tabular}

Notes: The first two numerical columns are forecasted and actual values of the variable in the first column, where the forecasts are computed using the factor model and the values of the factors through 2009q2. The third column is the shortfall (the negative of the forecast error), and the final column gives the standard error of the shortfall arising solely from sampling error in the estimated model parameters. 
Table 5. Expected and Unexpected Contributions to GDP growth: NIPA Demand Components

\begin{tabular}{|c|c|c|c|c|c|c|c|c|c|c|c|}
\hline \multirow[b]{4}{*}{ Real gross domestic product } & \multirow{3}{*}{$\begin{array}{l}\text { Growth } \\
\text { Rate, } \\
\text { 2009Q2- } \\
\text { 2016Q2 }\end{array}$} & \multirow{3}{*}{$\begin{array}{c}\text { Average } \\
\text { Share }\end{array}$} & \multicolumn{6}{|c|}{ Okun's Law Cyclical Adjustment } & \multirow{2}{*}{\multicolumn{3}{|c|}{ DFM Forecast }} \\
\hline & & & \multirow[b]{2}{*}{$\begin{array}{l}\text { Okuns law } \\
\text { coefficient } \\
\text { (SE) }\end{array}$} & \multicolumn{5}{|c|}{ CA Growth Rate } & & & \\
\hline & & & & \begin{tabular}{|c|} 
Three \\
previous \\
recoveries
\end{tabular} & $\begin{array}{c}\text { Post-crisis } \\
\text { recovery }\end{array}$ & $\begin{array}{c}\text { Total } \\
\text { Shortfall }\end{array}$ & $\begin{array}{c}\text { Trend } \\
\text { shortfall }\end{array}$ & $\begin{array}{l}\text { Irregular } \\
\text { (z) } \\
\text { shortfall }\end{array}$ & Forecast & Shortfall & $\mathrm{SE}$ \\
\hline & 2.06 & 1 & $-1.49(0.18)$ & 2.95 & 0.96 & 1.99 & 1.26 & 0.73 & 2.63 & 0.57 & 0.07 \\
\hline Personal consump. Expend. & 1.54 & 0.68 & $-0.74(0.14)$ & 2.00 & 1.04 & 0.96 & 0.70 & 0.26 & 1.80 & 0.26 & 0.04 \\
\hline Goods & 0.78 & 0.23 & $-0.44(0.08)$ & 0.80 & 0.48 & 0.32 & 0.24 & 0.08 & 0.86 & 0.08 & 0.03 \\
\hline Goods, durable & 0.47 & 0.07 & $-0.25(0.06)$ & 0.43 & 0.28 & 0.15 & 0.12 & 0.03 & 0.50 & 0.03 & 0.03 \\
\hline Motor vehicles \& parts & 0.11 & 0.02 & $-0.09(0.04)$ & 0.10 & 0.04 & 0.06 & 0.09 & -0.03 & 0.10 & -0.01 & 0.02 \\
\hline Furn. \& dur. HH eqpt & 0.11 & 0.02 & $-0.06(0.01)$ & 0.08 & 0.06 & 0.02 & 0.02 & 0.00 & 0.10 & 0.00 & 0.00 \\
\hline Recreat. goods \& vehicles & 0.20 & 0.02 & $-0.06(0.01)$ & 0.21 & 0.15 & 0.06 & 0.02 & 0.04 & 0.24 & 0.04 & 0.01 \\
\hline Other durables & 0.05 & 0.01 & $-0.03(0.01)$ & 0.05 & 0.03 & 0.02 & 0.00 & 0.01 & 0.06 & 0.01 & 0.00 \\
\hline Goods, nondurable & 0.32 & 0.15 & $-0.19(0.03)$ & 0.38 & 0.20 & 0.18 & 0.13 & 0.05 & 0.37 & 0.05 & 0.01 \\
\hline Food \& beve. off premises & 0.06 & 0.05 & $-0.03(0.02)$ & 0.08 & 0.03 & 0.04 & 0.03 & 0.01 & 0.08 & 0.02 & 0.00 \\
\hline Clothing \& footwear & 0.06 & 0.02 & $-0.05(0.01)$ & 0.12 & 0.03 & 0.09 & 0.07 & 0.02 & 0.08 & 0.02 & 0.01 \\
\hline Gasoline \& energy & 0.00 & 0.02 & $-0.03(0.01)$ & 0.03 & -0.02 & 0.04 & 0.02 & 0.02 & 0.00 & 0.00 & 0.01 \\
\hline Other nondurable goods & 0.19 & 0.06 & $-0.07(0.01)$ & 0.15 & 0.15 & 0.00 & 0.00 & 0.00 & 0.19 & 0.00 & 0.01 \\
\hline Services & 0.76 & 0.46 & $-0.30(0.08)$ & 1.21 & 0.57 & 0.64 & 0.46 & 0.18 & 0.93 & 0.18 & 0.02 \\
\hline Housing \& utilities & 0.13 & 0.13 & $-0.06(0.02)$ & 0.28 & 0.10 & 0.18 & 0.12 & 0.07 & 0.20 & 0.07 & 0.01 \\
\hline Health care & 0.31 & 0.11 & $0.00(0.03)$ & 0.23 & 0.31 & -0.08 & -0.07 & -0.01 & 0.31 & 0.00 & 0.01 \\
\hline Transportation services & 0.04 & 0.02 & $-0.08(0.01)$ & 0.07 & 0.00 & 0.07 & 0.06 & 0.01 & 0.03 & -0.01 & 0.00 \\
\hline Recreational services & 0.04 & 0.03 & $-0.04(0.01)$ & 0.09 & 0.02 & 0.07 & 0.05 & 0.03 & 0.06 & 0.02 & 0.00 \\
\hline Food serv. \& accomm. & 0.11 & 0.04 & $-0.06(0.02)$ & 0.09 & 0.08 & 0.01 & 0.01 & 0.00 & 0.11 & 0.00 & 0.01 \\
\hline Fin. services \& insurance & 0.00 & 0.05 & $-0.02(0.04)$ & 0.18 & -0.03 & 0.21 & 0.16 & 0.05 & 0.06 & 0.07 & 0.01 \\
\hline Other services & 0.10 & 0.06 & $-0.06(0.02)$ & 0.15 & 0.06 & 0.09 & 0.07 & 0.02 & 0.11 & 0.01 & 0.01 \\
\hline NPISH & 0.03 & 0.02 & $0.02(0.01)$ & 0.12 & 0.05 & 0.07 & 0.05 & 0.02 & 0.06 & 0.03 & 0.01 \\
\hline Gross priv. dom. investment & 0.91 & 0.15 & $-1.11(0.14)$ & 0.63 & 0.03 & 0.60 & 0.45 & 0.15 & 0.89 & -0.02 & 0.04 \\
\hline Fixed private investment & 0.70 & 0.15 & $-0.94(0.07)$ & 0.53 & 0.09 & 0.43 & 0.41 & 0.03 & 0.59 & -0.11 & 0.03 \\
\hline Nonresidential & 0.50 & 0.12 & $-0.69(0.08)$ & 0.47 & 0.13 & 0.34 & 0.26 & 0.08 & 0.48 & -0.02 & 0.02 \\
\hline Structures & -0.01 & 0.03 & $-0.19(0.03)$ & -0.01 & -0.06 & 0.05 & 0.02 & 0.03 & 0.00 & 0.01 & 0.01 \\
\hline Equipment & 0.38 & 0.06 & $-0.44(0.05)$ & 0.30 & 0.09 & 0.20 & 0.17 & 0.03 & 0.33 & -0.05 & 0.02 \\
\hline Intell. property products & 0.14 & 0.04 & $-0.06(0.01)$ & 0.19 & 0.11 & 0.07 & 0.06 & 0.02 & 0.15 & 0.01 & 0.01 \\
\hline Residential & 0.20 & 0.03 & $-0.25(0.05)$ & 0.07 & -0.03 & 0.10 & 0.15 & -0.05 & 0.12 & -0.08 & 0.02 \\
\hline Structures & 0.20 & 0.03 & $-0.25(0.05)$ & 0.07 & -0.03 & 0.10 & 0.15 & -0.05 & 0.11 & -0.08 & 0.02 \\
\hline Equipment & 0.00 & 0 & $0.00(0.00)$ & 0.00 & 0.00 & 0.00 & 0.00 & 0.00 & 0.00 & 0.00 & 0.00 \\
\hline Government expenditures & -0.19 & 0.19 & $0.10(0.06)$ & 0.45 & -0.11 & 0.56 & 0.31 & 0.25 & 0.12 & 0.31 & 0.03 \\
\hline Federal & -0.09 & 0.08 & $0.11(0.05)$ & 0.18 & -0.04 & 0.22 & 0.07 & 0.15 & 0.11 & 0.20 & 0.02 \\
\hline State \& local & -0.10 & 0.12 & $-0.01(0.03)$ & 0.26 & -0.07 & 0.34 & 0.24 & 0.10 & 0.02 & 0.12 & 0.01 \\
\hline Exports & 0.58 & 0.13 & $-0.27(0.08)$ & 0.60 & 0.36 & 0.24 & 0.10 & 0.14 & 0.60 & 0.03 & 0.04 \\
\hline Imports & -0.76 & -0.16 & $0.54(0.09)$ & -0.70 & -0.34 & -0.36 & -0.29 & -0.08 & -0.77 & -0.01 & 0.03 \\
\hline \multicolumn{12}{|l|}{ Addendum: } \\
\hline $\begin{array}{l}\text { Government cons. expend. + } \\
\text { transfer payments }\end{array}$ & 0.66 & & $1.22(0.52)$ & 3.67 & 1.33 & 2.34 & 0.91 & 1.44 & 2.86 & 2.20 & 0.23 \\
\hline
\end{tabular}

Notes: Indented components add to the final entry at the prior level of indentation. 
Table 6: Test Statistics for a Break in the Mean Growth Rate in TFP

\begin{tabular}{|c|c|c|c|c|c|}
\hline & \multicolumn{3}{|c|}{ QLR (sup-Wald) test } & \multirow{2}{*}{ Nyblom test } & \multirow{2}{*}{ LFST tes } \\
\hline & 1 break & 2 breaks & 3 breaks & & \\
\hline \multirow[t]{2}{*}{$\begin{array}{l}\text { A. 1956-2016 } \\
p \text {-value for } \mathrm{H}_{0}: \mu_{t}=\mu \\
\text { Estimated break dates }\end{array}$} & $\begin{array}{c}0.01 \\
1973 Q 1\end{array}$ & $\begin{array}{c}0.06 \\
1973 Q 1 \\
2006 Q 1\end{array}$ & $\begin{array}{c}0.01 \\
\text { 1973Q1 } \\
\text { 1995Q4 } \\
\text { 2006Q1 }\end{array}$ & 0.02 & 0.03 \\
\hline & $\begin{array}{c}0.11 \\
(0.03,0.36)\end{array}$ & & & $\begin{array}{c}0.11 \\
(0.02,0.40)\end{array}$ & \\
\hline \multirow[t]{2}{*}{$\begin{array}{l}\text { B. 1981-2016 } \\
p \text {-value for } \mathrm{H}_{0}: \mu_{t}=\mu \\
\text { Estimated break dates }\end{array}$} & $\begin{array}{c}0.38 \\
2006 Q 1\end{array}$ & $\begin{array}{c}0.14 \\
1995 Q 1 \\
\text { 2006Q1 }\end{array}$ & $\begin{array}{c}0.25 \\
1988 Q 1 \\
1995 Q 4 \\
\text { 2006Q1 }\end{array}$ & 0.35 & 0.31 \\
\hline & $\begin{array}{c}0.05 \\
(0.0,0.15)\end{array}$ & & & $\begin{array}{c}0.05 \\
(0.0,0.27)\end{array}$ & \\
\hline
\end{tabular}

Notes: All test are of a constant mean against a non-constant alternative: for the QLR, regime changes; for the Nyblom, against random walk drift; for the LFST, against more general martingale variation. All tests are heteroskedasticity and autocorrelation-robust. The final two rows in each block provide the point estimate of the standard deviation of a random walk drift in the mean, $\sigma_{\Delta \mu}$, and its $90 \%$ confidence interval based on inverting the test statistic.

Table 7: Industry Growth by Subperiod

\begin{tabular}{|c|c|c|c|c|c|c|c|c|}
\hline & & $\begin{array}{r}\text { Pre- } \\
1995\end{array}$ & $\begin{array}{r}1995- \\
2000 \\
\end{array}$ & $\begin{array}{r}2000- \\
2004 \\
\end{array}$ & $\begin{array}{r}2004- \\
2007 \\
\end{array}$ & $\begin{array}{r}2007- \\
2014 \\
\end{array}$ & $\begin{array}{r}\text { Change } \\
\text { after } 2004 \\
(\mathrm{~d}-\mathrm{c})\end{array}$ & VA Weight \\
\hline & & (a) & (b) & (c) & (d) & (e) & $(\mathrm{f})$ & (g) \\
\hline \multicolumn{2}{|c|}{ (1) Private business } & 0.62 & 1.35 & 2.05 & 0.32 & 0.26 & -1.73 & 100.0 \\
\hline (2) & Finance and Insurance & -0.48 & 3.37 & 0.89 & 0.27 & 0.22 & -0.63 & 8.3 \\
\hline (3) & Energy (Oil/gas, pipeline, refining, utilities) & 3.15 & -3.47 & 5.55 & -3.51 & 3.14 & -9.06 & 5.9 \\
\hline (4) & Transportation (ex. pipelines) & 3.47 & 2.34 & 2.57 & 2.78 & 0.40 & 0.21 & 2.5 \\
\hline (5) & Construction & 0.17 & -1.29 & -0.82 & -5.50 & -0.62 & -4.67 & 6.0 \\
\hline (6) & IT producing & 8.47 & 14.46 & 7.23 & 6.78 & 2.49 & -0.45 & 5.7 \\
\hline \multicolumn{2}{|c|}{ (7) Business ex. finance } & 0.71 & 1.17 & 2.17 & 0.34 & 0.28 & -1.84 & 91.7 \\
\hline & Finance intensive & 0.22 & 0.24 & 1.35 & -0.03 & 0.57 & -1.37 & 44.7 \\
\hline & Non-finance intensive & 1.16 & 2.03 & 2.95 & 0.67 & -0.03 & -2.28 & 47.0 \\
\hline \multicolumn{2}{|c|}{ (10) Business ex. finance and IT prod } & 0.25 & 0.23 & 1.84 & -0.10 & 0.12 & -1.93 & 86.0 \\
\hline & IT-intensive & 0.39 & 0.96 & 2.19 & 0.86 & -0.22 & -1.33 & 42.8 \\
\hline & Non-IT-intensive & 0.11 & -0.52 & 1.49 & -0.99 & 0.45 & -2.49 & 43.2 \\
\hline
\end{tabular}

Notes: Industry and aggregate growth based on BLS 60-industry MFP data. Entries are percent change per year, except for value-added weight, which is average percentage share from 1988-2014. 
Table 8: Panel Regressions of Industry TFP Growth on Regulatory Restrictions

\begin{tabular}{|c|c|c|c|c|}
\hline & $(1)$ & $(2)$ & $(3)$ & $(4)$ \\
\hline Regulation $_{i, t}$ & 0.032 & 0.033 & & \\
& $(0.032)$ & $(0.033)$ & & \\
\hline Regulation $_{i, t-1}$ & -0.023 & -0.011 & & \\
& $(0.027)$ & $(0.026)$ & & \\
\hline Regulation $_{i, t-2}$ & -0.045 & -0.036 & & \\
& $(0.039)$ & $(0.035)$ & & \\
\hline Regulation $_{i, t-3}$ & 0.022 & 0.036 & & -0.009 \\
& $(0.023)$ & $(0.034)$ & & $(0.036)$ \\
\hline Regulation $_{i, t: t-2}$ & & & -0.018 & 0.060 \\
& & & $(0.040)$ & $(0.050)$ \\
\hline Regulation $_{i, t-3: t-5}$ & & & & Yes \\
\hline Industry Fixed Effects & Yes & Yes & Yes & Yes \\
\hline Year Fixed Effects & No & Yes & Yes & \\
\hline F-statistics for Regulation $(p$-value $)$ & $0.36(0.83)$ & $0.44(0.78)$ & $0.19(0.67)$ & $0.86(0.43)$ \\
\hline
\end{tabular}

Notes: Data are annual observations of industry TFP growth (the dependent variable) and regulations for the 42 industries for which Regdata has an index of regulation, 1988-2014. Standard errors (in parentheses) are clustered by industry. $\overline{\text { Regulation }}_{i, t: t-2}$ denotes the average value of Regulation for lags 02, and $\overline{\text { Regulation }}_{i, t-3: t-5}$ is defined analogously.

Table 9: Changes in Weekly Hours of Time Use, 2007 to 2015, People 15 and Older

\begin{tabular}{lccccc}
\hline \hline & $\begin{array}{c}\text { Personal } \\
\text { care, } \\
\text { including } \\
\text { sleep }\end{array}$ & $\begin{array}{c}\text { Market } \\
\text { work }\end{array}$ & Education & Leisure & Other \\
\hline Men & 2.0 & -2.4 & 0.5 & 0.7 & -0.8 \\
Women & 2.4 & -1.5 & 0.1 & 0.7 & 0.8 \\
\hline \hline
\end{tabular}

Source: American Time Use Survey. 